\title{
Narrativas de histórias: um estudo preliminar na gestão de projetos de tecnologia da informação
}

\author{
Valério Brusamolin \\ Doutorando em ciência da informação. \\ E-mail: brusamolin@gmail.com \\ Eduardo Moresi \\ Doutor em ciência da informação, professor \\ da Universidade Católica de Brasília. \\ E-mail:moresi@ucb.br
}

\section{Resumo}

Narrativas de histórias é uma técnica de gestão do conhecimento para compartilhamento de experiências, pensamentos e valores no ambiente organizacional. 0 objetivo desta pesquisa foi identificar 0 emprego de narrativas de histórias para transpor as barreiras que se interpõem ao sucesso de projetos de tecnologia de informação (TI). Como resultado, apresenta-se uma proposta de emprego de narrativas de histórias para facilitar o gerenciamento de projetos na área da TI.

\section{Palavras-chave}

Gerenciamento de projetos. Gestão do conhecimento. Narrativas de histórias organizacionais.

\section{Historical narratives: a preliminary study on management of projects of information technology}

\section{Abstract}

Historical narratives are a technique of knowledge management for sharing experiences, thoughts and values in the organizational environment. The objective of this research is to identify the use of historical narratives for overcoming the barriers which hinder the success of projects of Information Technology (IT). As a result, a proposal has been presented for use of historical narratives for facilitating the management of IT projects.

\section{Keywords}

Project management. Knowledge management. Organizational storytelling.

\section{INTRODUÇÃO}

Projetos de tecnologia da informação (TI) normalmente envolvem aprendizado, seja na aquisição de novas tecnologias, em que deve ser desenvolvido um trabalho interno pelo gerente, seja nas mudanças decorrentes da implantação de novo sistema no ambiente do usuário. Nessas duas situações, convém que o gerente tenha domínio de alguma técnica que o auxilie a fertilizar o ambiente para a mudança ou aquisição de novos conhecimentos.

O papel do gerente consiste fundamentalmente em participar de conversações, atuando na promoção de algumas e evitando outras (ECHEVERRÍA, 1997, p. 264). Em suas palavras, o autor mostra o que deve nortear a atuação de um gerente na era do conhecimento: transformar não por meio da imposição, mas pelo diálogo. O papel de capataz do gerente é inadequado ao trabalho do conhecimento: o novo gerente deve ser um líder de líderes, um sedutor que possui habilidades conversacionais, capaz de obter alto desempenho de sua equipe estimulando conexões entre os integrantes (ECHEVERRIA, 2004).

Não somente Echeverría, mas também outros autores (CAMILLE, WILLIAN, 2004; DENNING, 2005; ABMA, 2003; DENNEHY, 2001; GARGIULO, 2005; KAHAN, 2001; STEIN, 1995) destacam a importância das conversações e histórias, mas a sua aplicabilidade ao ambiente de tecnologia é recente, de modo que pouco se sabe sobre o como aplicar tais conhecimentos em situações reais.

Contudo, a capacidade das organizações em mudar e adaptarse nunca foi tão importante como nos dias de hoje. Narrar histórias é uma abordagem bastante poderosa para comunicar iniciativas de mudança, de modo que as pessoas envolvidas sintam-se parte de uma empresa que está tentando chegar a um lugar melhor (TERRA, 2002, p. 151).

No contexto do gerenciamento de projetos, a primeira edição do $\operatorname{PMBOK}^{\circledR}{ }^{1}(2000$, p. 21-26) lista e conceitua as seguintes

10 Project Management Body of Knowledge, também conhecido como PMBOK® é um conjunto de práticas em gerência de projetos levantado pelo Project Management Institute (PMI) e constitui a base da metodologia de gerência de projetos do PMI. Estas práticas são compiladas na forma de um guia, chamado Guia do Conjunto de Conhecimentos em Gerenciamento de Projetos, ou Guia PMBOK. 
habilidades essenciais do gerente: liderança, resolução de problemas e influência no ambiente organizacional. Entretanto, coloca a aplicação de tais habilidades fora do seu escopo, explicando que já estão documentadas na literatura sobre administração geral. Em sua terceira edição (2004), essa restrição não foi explicitada, mas a abordagem sobre o tema foi reduzida a apenas uma página $(2004$, p.15), demonstrando que não se pretende incorporar tal assunto ao escopo do compêndio.

Foi realizada uma revisão de literatura na qual se evidenciou a ausência de trabalhos e pesquisas sobre o tema. A tabela 1 apresenta uma síntese dos resultados obtidos.

Tabela 1

\section{Resultado de pesquisa em bases de dados.}

\begin{tabular}{l|c|c}
\hline \multicolumn{1}{c|}{ Termos Bases de Dados" } & $\begin{array}{c}\text { Web of } \\
\text { Science }\end{array}$ & Scirus \\
\hline "knowledge management" & 2.679 & 4.208 \\
\hline "project management" & 2.442 & 8.805 \\
\hline $\begin{array}{l}\text { "storytelling" } \\
\text { "knowledge management" AND "project } \\
\text { management" AND "storytelling" }\end{array}$ & 1.065 & 1.360 \\
\hline
\end{tabular}

* Bases pesquisadas: Scirus (http://www.scirus.com) e Web of Science (http:// apps.isiknowledge.com), em 22/02/2008.

Os assuntos gestão do conhecimento, gestão de projetos e narrativas de histórias apresentaram 12 referências nas bases pesquisadas, sendo uma delas revisão de livro (STYHRE, 2003).

A narrativa de histórias possui várias possibilidades de uso no ambiente organizacional, e a literatura atesta o seu valor. Schindler e Eppler (2003) recomendam o emprego de técnicas de narrativas na redação de histórias de aprendizagem de projetos. Kamara Anumba e Carillo (2002) propõem um método de gestão do conhecimento no qual a narrativa é citada como uma das abordagens estabelecidas para a transferência do conhecimento. Woo et al., (2003) citam o emprego de narrativas de histórias para o compartilhamento do conhecimento tácito na indústria de construção civil.

Os estudos com foco em gestão de projetos trazem várias contribuições sobre narrativas de histórias nas organizações, o que demonstra interesse crescente nesse método de lidar com o conhecimento tácito (STYHRE, ROTH, INGELGARD, 2002) e o significado de conhecimento produzido em uma organização ou entre organizações (CORVELLEC, RISBERG, 2007). Burkhard e Meier (2005) e Whyte et al., (2008) apresentam abordagens de gestão do conhecimento nas quais utilizam técnicas de visualização gráfica para o compartilhamento do conhecimento no gerenciamento de projetos. Lathi e Beyerlein (2000) analisaram como a gestão e a transferência do conhecimento influenciam no desempenho de empresas de consultoria. Styhre, Roth e Ingelgard (2002) desenvolveram um método para criação de conhecimento considerando perspectivas de senso comum e de relacionamento interpessoal, como resultado de estudo realizado em grande empresa farmacêutica.

Como as organizações têm perdido significativos recursos na implementação de projetos de software, Petter e Vaishnavi (2008) desenvolveram um método para reutilizar as experiências na forma de narrativas, a partir de princípios de gestão do conhecimento. Lutters e Seaman (2007) desenvolveram um método para usar histórias de guerra em projetos de manutenção de software.

Não foi encontrada fonte que associasse áreas de conhecimento do PMBOK® ou habilidades nele descritas com o emprego de narrativas. Nenhuma referência apresenta pesquisa quantitativa sobre uso de narrativas por gerentes de TI. O presente trabalho pretende preencher estas lacunas, investigando o uso que os gerentes de projeto de TI fazem da técnica de narrativas, e para isso a classificação das histórias levantada na literatura foi empregada na confecção do instrumento de coleta de dados.

\section{REFERENCIAL TEÓRICO}

\section{Projetos de TI}

Segundo consta no PMBOK® $(2004$, p. 8), gerenciamento de projetos é a aplicação de conhecimentos, habilidades e técnicas para projetar atividades que visem a atingir os requisitos de um projeto.

Os projetos de TI sempre envolvem mudanças e têm de vencer resistências. O gerente é o principal responsável pelo sucesso e deve atuar de forma influente no ambiente organizacional, interagindo com pessoas por meio de conversas, portanto, deve desenvolver habilidades conversacionais para efetivo desempenho. A narrativa de histórias é uma técnica poderosa para o compartilhamento de visões e propósitos, e algumas pessoas parecem saber como utilizá-las com efetividade para atingir seus objetivos (BURKHARD, MEIER, 2005; WHYTE et al., (2008)

A adoção de técnicas de gerenciamento de projeto foi incorporada à engenharia de software devido ao grande número de fracassos em grandes projetos nas décadas de 60 e 70 . Entretanto, Sommerville (2003, p. 60) deixa transparecer que algo não vai bem no gerenciamento de projetos de TI. Ele os distingue de outros tipos de projetos de engenharia, citando as seguintes dificuldades como justificativas para atrasos em cronogramas e ultrapassagem de orçamento: 
- o produto é intangível: o software não pode ser visto ou tocado, de modo que os gerentes dependem de outras pessoas para produzir (de forma subjetiva) a documentação que atesta o progresso obtido;

- não há um processo de software padrão: são vários os processos de software, mas não há uma compreensão clara das relações entre o processo e os tipos de produto;

grandes projetos de software são, freqüentemente, projetos únicos: as lições aprendidas com experiências anteriores podem não ser válidas para novos projetos, pois as rápidas evoluções tecnológicas desatualizam o conhecimento prévio.

Projetos de TI envolvem processos complexos cujo conhecimento encontra-se disperso entre várias pessoas e fundamenta-se na experiência. É o denominado conhecimento tácito, motivo de vários projetos bem-sucedidos na coleta e armazenamento, mas pobres na disseminação e troca de conhecimentos. Isso porque a socialização é a forma mais bem-sucedida na transmissão do conhecimento tácito (WOO et al., 2003). Meyers e Wilemon (2002) destacam que a disseminação de histórias com lições importantes é fator determinante no sucesso de equipes de organizações que lidam com tecnologia.

O aprendizado é um subproduto importante do projeto de TI, e os erros devem ser registrados para que não se repitam. Schindler (2003) propõe o registro sistemático de problemas ocorridos em projetos para auxiliar na redução de riscos, conduzindo a uma vantagem competitiva sustentável. $\mathrm{O}$ autor reconhece que as pessoas não são propícias a documentar suas falhas, fato também descrito por Willians (2003), que propõe formas de captura e distribuição das lições aprendidas. Histórias de fracassos anteriores instruem para o sucesso no presente; o fracasso seria um conceito relativo, pois analisado em um contexto mais amplo no tempo, pode ser um passo necessário para o sucesso (STAVRI, 2003).

Denning (2004a) afirma que as histórias negativas causam mais impacto na audiência e chega até a recomendar cuidado com histórias positivas, pois podem dar margem às anti-histórias: chacotas ou piadas sobre o que foi contado. Rhodes (apud TAYLOR et al., 2002) constatou que o sucesso ou fracasso não reside no evento em si, mas sim na forma como as histórias são contadas. Recomenda-se atenção do gerente para as histórias que se contam sobre o projeto de sua responsabilidade, pois elas fornecem valiosas informações sobre expectativas oficiais e não oficiais do projeto, o que pode originar muitos problemas. O gerente pode atuar, por sua vez, expondo as próprias histórias para controlar expectativas, levando a uma recepção mais positiva na conclusão do projeto. Se o gerente não contar suas histórias, a coletividade as criará (AMTOFT, 2002).
A gestão de mudanças também faz parte do dia-a-dia de um gerente de projetos de TI, pois a tecnologia tanto provoca mudanças no ambiente do usuário, quanto sofre com a evolução tecnológica. Hall e Adriani (2003) abordam questões e conceitos de gestão do conhecimento em ambientes voltados para a inovação, visando a um aprimoramento no gerenciamento de projetos. Carrol (2002) analisa o uso estratégico das narrativas de histórias sobre o passado e futuro na mudança organizacional. A mudança ocorre juntamente com o aprendizado organizacional e, segundo Abma (2003), workshops de narrativas de histórias podem ser empregados como técnica de intervenção no ambiente para facilitar o aprendizado, o que pode ser encarado como um processo coletivo e relacional.

\section{Narrativas de Histórias}

A palavra história pode ser empregada em qualquer situação, abolindo o neologismo "estória" (CEGALLA, 1999, p. 154) proposto em 1942 com o intuito de diferenciar o folclore da ciência, como acontece no idioma inglês, que possui as palavras history e story.

Narrativas de histórias são relatos orais de um ou mais eventos, verdadeiros ou fictícios. A diferença entre uma história e a citação de um exemplo está na adição de conteúdo emocional e detalhes sensoriais na narrativa.

Uma narrativa de história compreende detalhes, personagens e eventos em um todo que é maior do que a soma das partes (SIMMONS, 2001, p. 31), podendo ser tão curta como uma simples frase (GARGIULO, 2005, p. 10). É uma forma fundamental de comunicação, capaz de atrair a atenção dos ouvintes. Reforçar um ponto de vista com uma história é muito mais convincente. Gargiulo (2005, p. 8) cita as seguintes palavras como possíveis sinônimos de histórias: anedota; conversação; experiência; memória; conto; imagem; mito; parábola; metáfora; fábula; analogia; ilustração; clichê; alegoria; narrativa; piada; instantâneo; cena.

Portanto, o conceito de história é intuitivo, e o ser humano consegue entender e contar histórias já aos dois anos de idade, antes mesmo de desenvolver o raciocínio lógico. A estrutura neurológica para a compreensão de histórias é uma característica básica da consciência, despertada espontaneamente antes mesmo de aprendermos a falar (DENNING, 2005, p. 6-7).

Segundo Lipman (1999, p. 17), uma narrativa de história propicia a transferência de imagens mentais entre narrador e audiência através da "ponte" que é a história, construída com os "tijolos" da linguagem oral. Essas imagens mentais permitem um contexto compartilhado entre narrador e audiência, constituindo uma base para a comunicação. 
A figura 1 ilustra o que Lipman denomina "triângulo da narrativa de histórias", composto pelos vértices: o narrador, a história e a audiência, envolvidos em um mesmo contexto. As conexões contínuas denotam relacionamentos que podem ser controlados. O narrador pode elaborar a sua história, selecioná-la e escolher a sua audiência, mas a forma como a audiência vai se relacionar com a história não pode ser controlada. É necessário ter a humildade de deixar a audiência compreender a história da sua maneira.

\section{Figura 1}

\section{0 triângulo da narrativa de histórias.}

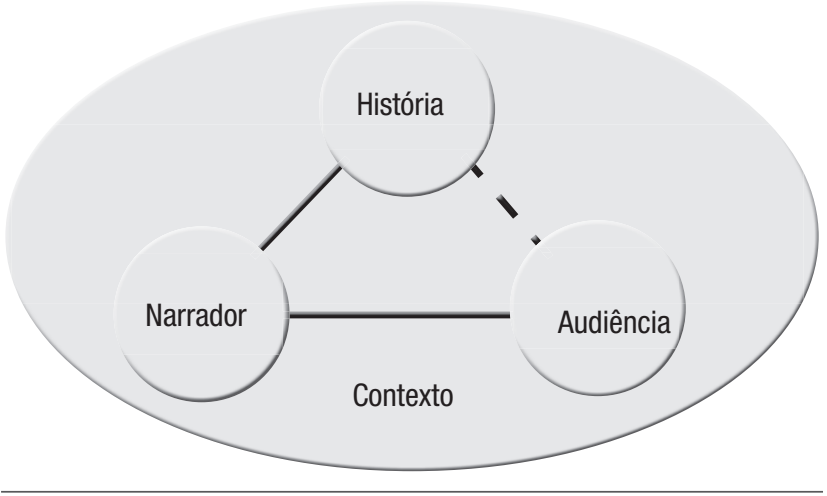

Fonte: Lipman (1999, p.18).

Portanto, os resultados obtidos com uma narrativa de história não são completamente previsíveis (GARGIULO, 2005, p. 17). As histórias possuem, entretanto, a capacidade de lidar bem com a complexidade: uma boa narrativa é dinâmica e desenvolve-se no imaginário de quem a ouve, conduzindo a um nível de compreensão por vezes até superior ao do narrador.

Com uma história, é possível estabelecer um contexto comum, facilitando a compreensão do que está sendo comunicado. Maturana (1997, p. 155-160) explica que a dificuldade de comunicação entre seres humanos ocorre porque os seres vivos são autopoiéticos, isto é, construídos por si mesmos e constituem-se em sistemas fechados, não oferecendo condições para a descrição de uma realidade objetiva. Conseguimos nos comunicar pela troca de palavras que possuem significados compartilhados, aprendidos através da experiência. Contudo, para uma comunicação eficaz, é necessário conhecer a audiência, saber as experiências por que passou e como as histórias serão por ela interpretadas. É necessário conhecer o contexto.

O poder das histórias para incentivar as crenças é constatado pela pesquisa empreendida pelas sociólogas Joanne Martin e Melanie Powers (1983 apud KOUZES, 1997, p. 241). Elas compararam a capacidade de persuasão de quatro métodos diferentes para convencer os alunos de mestrado em administração comercial que participavam de seu estudo em que determinada empresa praticava uma política de evitar demissões. Em uma situação, utilizaram uma história para persuadir as pessoas; na segunda situação, apresentaram dados estatísticos; na terceira situação, usaram dados estatísticos e história; e na quarta, utilizaram uma declaração de política da empresa. Os alunos dos grupos que ouviram a história acreditaram na afirmação sobre a política empresarial mais do que todos os outros grupos. Outras pesquisas também demonstram que a informação, quando é apresentada primeiramente sob a forma de exemplo ou história, é lembrada de maneira mais rápida e acurada.

Narrar e ouvir histórias é um processo de socialização de conhecimento tácito que desenvolve um campo de interação e atua como um facilitador do compartilhamento de experiências e modelos mentais do grupo (NONAKA; TAKEUCHI, , 1997, p. 80). Traz à mente a metáfora de uma reunião tribal em que um grupo de pessoas em torno de uma fogueira, cada qual com sua própria visão dos acontecimentos, compartilham seus próprios estilos de narrativas.

No entanto, é preciso reconhecer que o uso da técnica de narrativas é inadequada para a transmissão de habilidades críticas, inclusive conhecimento aprofundado sobre um domínio específico (SWAP et al., p. 97, 103-104). Isso se deve ao fato de que o narrador não possui controle sobre a forma como a história será interpretada pela audiência (LIPMAN, 1999). Em algumas situações seu emprego também pode ser contraproducente, como nos seguintes exemplos (DENNING, 2005a): quando a audiência não deseja uma história, pode ser que ela queira ver informações demonstradas por meio de números, e nesse caso uma história pode ser mal recebida; onde uma análise for mais adequada, uma história pode suplementar o pensamento abstrato, mas não deve substituí-lo; quando a história não estiver preparada, por isso recomendase treinamento antes de narrar uma história para um público importante; quando a história for falsa, o ganho em curto prazo não compensa a perda da credibilidade em longo prazo.

As histórias são com freqüência as fontes mais importantes de lições morais sobre o que devemos ou não valorizar e sobre comportamentos que devemos ter na organização. As ações dos gestores tornam-se histórias que passam de pessoa para pessoa e confirmam ou não os princípios de gestão explicitados em códigos de ética. Essas narrativas falam de acontecimentos que deixaram uma marca indelével nos colaboradores de uma organização. São aprendizados vivenciados, recordados e recontados várias vezes.

\section{Narrativas de Histórias no Gerenciamento de Projetos}

O uso da técnica de narrativas por gestores ocorre com freqüência, como foi identificado em uma pesquisa realizada em vários países (SWAP et al., p. 97, 104). Provavelmente, o 
seu emprego se dá de forma natural, pois acontece em várias culturas e em diferentes países.

Todavia, a narrativa pode reconstruir a autenticidade, pois permite ao narrador não recitar simplesmente abstrações formuladas por outros, mas a articulação de idéias que representam uma criação única (DENNING, 2004). Assim, quando o gestor conta uma história, constrói uma camaradagem com a equipe por meio do compartilhamento da sua experiência, o que conduz a percepções de confiança críticas para a obtenção de informações sensíveis.

Mesmo quando a história não for autêntica, caso de uma fábula, há boa representação de uma verdade, considerando que uma boa história possui credibilidade maior do que um simples fato. Ela envolve diversos fatores como quem, quando e como, entrelaçando relações complexas entre fatos, tempo, espaço e valores (SIMMONS, 2001, p. 33-35). O antigo mote italiano de que "se não é verdadeiro, é bem contado" sintetiza bem a forte tendência que temos de acreditar em uma história.

Prusak (2004), ilustrando o valor das narrativas no contexto organizacional, conta a seguinte história:

...quando trabalhava na IBM, participei de uma reunião com o CEO da empresa, Lou Gerstner. "O que faz um CEO que outros não fazem?", "Por que é tão regiamente remunerado?", me questionava. Observando atentamente a personalidade de Gerstner, julguei que não havia nada de excepcional quanto ao carisma e simpatia; foi na sala de reunião que o $\mathrm{CEO}$ revelou o seu valor, ao demonstrar ser um grande contador de histórias. Não histórias factuais, mas histórias sobre o futuro da IBM, sobre o que a empresa iria fazer, compartilhando a sua visão com seus assessores e também executivos de outras empresas.

Kahan (2001, p. 26) reconhece empregar conscientemente narrativas no seu trabalho. Diz ele que quando conta isso às pessoas, normalmente recebe olhares confusos e perguntas sobre o que tem a ver narrativas de histórias com negócios. "Muito mais do que você possa imaginar" é a resposta. Para ele, negociar é persuadir, convencer o outro de que seu produto realmente é bom, vale o preço e é necessário.

Seja qual o motivo, uma narrativa de história é uma poderosa técnica de convencimento e persuasão (KAHAN, 2001, p. 26). McClokey (1998) ilustra a importância do assunto ao demonstrar que $28 \%$ do PIB norte-americano é obtido por meio da persuasão. Os economistas parecem estar descobrindo que somente matemática não ajuda a compreender fenômenos econômicos.

Dessa maneira, as histórias tornam-se um recurso estratégico efetivo para os gestores que percebem a relação entre contar histórias, criar e compartilhar conhecimento. Segundo Terra (2002, p. 151), se os gestores aprenderem a tornar suas histórias mais eficazes, poderão utilizá-las em seu potencial máximo. $\mathrm{O}$ mesmo autor cita as lideranças de gestão do conhecimento na Hill \& Knowlton, na Texaco e na Siemens, que constantemente buscam histórias inspiradoras para comunicá-las através de caminhos on-line e off-line.

Echeverría (1997) desperta para a importância da comunicação oral no ambiente organizacional nesses tempos de mudança constante. Segundo o autor, a escrita separou a conversa da ação. Como precisamos agir de imediato, antes da concorrência, não há mais tempo para escrever: temos de agir ao mesmo tempo que conversamos. Mais do que levar à ação, o autor postula que a identidade de um ser humano é constituída pelas histórias que conta acerca de si mesmo. Heidegger (apud ECHEVERRÍA, 1997, p.20-27) afirma que o homem não apenas constrói suas histórias, mas também é produto delas: "não podemos escapar do tecido que criamos com nossas histórias".

O quadro 1 apresenta os instrumentos utilizados na comunicação organizacional quanto ao alvo e ao canal. Marcadas com um (*) e em negrito, estão as oportunidades de emprego de narrativas de histórias.

Quadro 1

\section{Dimensões da comunicação organizacional}

\begin{tabular}{|c|c|c|c|c|c|c|}
\hline \multirow{2}{*}{\multicolumn{3}{|c|}{$\begin{array}{c}\text { Classificação da } \\
\text { Comunicação }\end{array}$}} & \multicolumn{4}{|c|}{ Quanto ao Alvo } \\
\hline & & & Interno & Externo & Parceiro & Outro \\
\hline \multirow{3}{*}{ 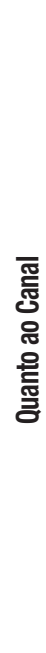 } & \multicolumn{2}{|c|}{ 픟 } & $\begin{array}{l}\text { Memorandos } \\
\text { Manuais } \\
\text { Intranet } \\
\text { Circulares } \\
\text { Posters }\end{array}$ & $\begin{array}{l}\text { ×Televisão } \\
\text { *Rádio } \\
\text { Anúncios } \\
\text { Balanços } \\
\text { Sítio Internet }\end{array}$ & $\begin{array}{l}\text { Portal B2B } \\
\text { SLA } \\
\text { Contratos } \\
\text { *Debriefings de } \\
\text { Projetos } \\
\text { *Conferência } \\
\end{array}$ & $\begin{array}{l}\text { Pesquisa de } \\
\text { Grupo Focal }\end{array}$ \\
\hline & \multirow{2}{*}{ 플 } & .त्तू & $\begin{array}{l}\text { *Treinamentos } \\
\text { *Reuniões } \\
\text { *Briefings }\end{array}$ & $\begin{array}{l}\text { Notícias e mídia } \\
\text { Mercado de } \\
\text { Trabalho } \\
\text { ×Grupos de } \\
\text { Usuários }\end{array}$ & $\begin{array}{l}\text { Lançamentos } \\
\text { Publicações }\end{array}$ & $\begin{array}{l}\text { Livros } \\
\text { Filantropia }\end{array}$ \\
\hline & & 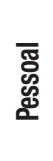 & $\begin{array}{l}\text { E-mail } \\
\star \text { *Telefone } \\
\text { *Conversa direta } \\
\text { *Reuniões }\end{array}$ & $\begin{array}{l}\text { E-mail } \\
\text { ^Telefone } \\
\text { *Interações } \\
\text { ad-hoc }\end{array}$ & $\begin{array}{l}\text { *Reuniões } \\
\text { *Telefone } \\
\text { E-mail }\end{array}$ & Networking \\
\hline
\end{tabular}

Fonte: Gargiulo (2005, p.25).

A figura 2, a seguir, ilustra os diferentes modos de conversão de conhecimento e o contexto das narrativas de histórias. A socialização ocorre quando o conhecimento tácito de uma pessoa é convertido em conhecimento tácito de outra pessoa, 
num contato pessoal (social), sem passar por um processo de externalização ou combinação prévios. A narrativa de histórias é uma técnica que pode ser empregada na gestão do conhecimento quando a socialização for o modo de conversão mais adequado.

Figura 2

Contexto da narrativa de histórias na conversão do conhecimento

\begin{tabular}{|c|c|c|c|}
\hline & $\begin{array}{l}\text { Conhecimento } \\
\text { Tácito }\end{array}$ & do & $\begin{array}{l}\text { Conhecimento } \\
\text { Explícito }\end{array}$ \\
\hline $\begin{array}{l}\text { Conhecimento } \\
\text { Tácito }\end{array}$ & $\begin{array}{l}\text { (Socialização) } \\
\text { Conhecimento } \\
\text { Compartilhado }\end{array}$ & & $\begin{array}{l}\text { (Externalização) } \\
\text { Conhecimento } \\
\text { Conceitual }\end{array}$ \\
\hline $\begin{array}{l}\text { Conhecimento } \\
\text { Explícito }\end{array}$ & $\begin{array}{c}\text { (Internalização) } \\
\text { Conhecimento } \\
\text { Operacional }\end{array}$ & & $\begin{array}{l}\text { (Combinação) } \\
\text { Conhecimento } \\
\text { Sistêmico }\end{array}$ \\
\hline
\end{tabular}

narrativas de histórias

Fonte: Nonaka e Takeuchi (1997, p. 81).

O modelo de Nonaka e Takeuchi mostra como o conhecimento organizacional é produzido, possibilitando a inovação. A habilidade das organizações em implementar mudanças é reconhecidamente importante já há décadas, mas a condução de um processo de mudança tem sido também reconhecidamente difícil de ser executado, pois as pessoas temem o desconhecido e normalmente sentem-se mais confortáveis ao fazer as coisas como vinham anteriormente fazendo (LUFTMAN, 2002).

Segundo Nonaka e Takeuchi (1997, p. 1), o sucesso das empresas japonesas é conseqüência da capacidade de "criação do conhecimento organizacional". Observadores ocidentais tendem a considerar a importância apenas do conhecimento explícito (documentado), enquanto empresas orientais percebem o conhecimento como sendo essencialmente tácito. A habilidade de contar e ouvir histórias é um processo socializador, que desenvolve um campo de interação e atua como um facilitador do compartilhamento de experiências e modelos mentais do grupo.

\section{Narrativas no Contexto do PMBOK}

O PMBOK® $(2004$, p. 13) organiza tais conhecimentos, habilidades e técnicas em cinco grupos distintos, denominados áreas de especialização: conjunto de conhecimentos em gerenciamento de projetos; conhecimentos, normas e regulamentos da área de aplicação; entendimento do ambiente do projeto; conhecimentos e habilidades de gerenciamento geral; habilidades interpessoais.

Conjunto de conhecimentos em gerenciamento de projetos

$\mathrm{O}$ "Conjunto de conhecimentos em gerenciamento de projetos" descreve o conhecimento exclusivo da área de gerenciamento de projetos sobreposto a outras disciplinas de gerenciamento. O PMBOK® (2004) é um subconjunto desses conhecimentos e consiste em definição do clico de vida do projeto; especificação de cinco grupos de processos de gerenciamento de projetos; especificação de nove áreas de conhecimento de gerenciamento de projetos.

As áreas de conhecimento consistem em gerenciamento de integração; gerenciamento de escopo; gerenciamento de tempo; gerenciamento de custo; gerenciamento de qualidade; gerenciamento de recursos humanos; gerenciamento de comunicações; gerenciamento de riscos; gerenciamento de aquisições.

\section{Conhecimentos, normas e regulamentos da área de aplicação}

Uma área de aplicação é uma categoria de projeto que possui características peculiares, nem sempre presentes em outras áreas. As áreas de aplicação geralmente são definidas em termos de departamentos funcionais, elementos técnicos, setores ou especializações em gerenciamento. Cada área em geral possui um conjunto de normas, práticas e procedimentos aceitos, que freqüentemente são externalizados em documentos.

\section{Entendimento do ambiente do projeto}

Os projetos estão inseridos em um contexto que abrange aspectos sociais, econômicos e ambientais, sobre os quais impõe impactos que devem ser considerados pela equipe de projeto:

- ambiente cultural e social: a equipe precisa entender como o projeto afeta as pessoas e como as pessoas afetam o projeto;

- ambiente internacional e político: pode-se fazer necessária a adaptação da equipe de projeto, ou parte dela, no que se refere a leis, normas, política e outras características específicas do ambiente onde será executado o projeto;

- ambiente físico: caso o projeto afete o ambiente físico, a equipe de gerenciamento deve tomar conhecimento da ecologia local e a geografia física que podem afetar ou serem afetadas pelo projeto.

\section{Conhecimentos e habilidades de gerenciamento geral}

Para que o gerente possa elaborar o planejamento, a organização, a formação de pessoal, a execução e o controle de operações de uma empresa, deve possuir conhecimento de disciplinas tais como: contabilidade e gerenciamento financeiro; compras e aquisições; vendas e marketing; contratos e legislação comercial; fabricação e distribuição; logística e cadeia de suprimento; planejamento estratégico, planejamento tático e planejamento operacional; estruturas organizacionais, comportamento organizacional, administração de pessoal, compensação, benefícios e planos de carreira; práticas de saúde e segurança; tecnologia da informação. 
Habilidades interpessoais

O PMBOK® (2004) lista as seguintes habilidades de relacionamento interpessoais como desejáveis para o gerente:

Liderança: a gerência se preocupa principalmente em "produzir resultados que atendam, de forma consistente, às principais expectativas das partes envolvidas", enquanto a liderança envolve:

- estabelecer direção - desenvolver ao mesmo tempo uma visão de futuro e as estratégias de mudanças para atingir esta visão;

- alinhar pessoas - comunicar esta visão, por meio de palavras e ações, às pessoas cuja cooperação possa ser necessária para atingir a visão;

- motivação e inspiração - ajudar as pessoas a adquirir energia para superar resistências a mudanças, que podem ser de caráter político, burocrático e relacionadas a recursos.

Em um projeto, espera-se que o gerente seja também o líder. A liderança necessita ser demonstrada em todos os níveis (liderança do projeto, liderança técnica e liderança de equipe).

Comunicação: comunicar envolve troca de informação entre emissor e receptor. A habilidade de comunicação está relacionada com o gerenciamento de comunicações do PMBOK®, mas não são a mesma coisa, pois a comunicação é tema abrangente e requer um corpo de conhecimento substancial que extrapola os objetivos da referida fonte. A comunicação possui as seguintes dimensões:

c oral e escrita, falada e ouvida;

- interna (dentro do projeto) e externa (ao cliente, à mídia, ao público, etc.);

- formal (relatórios, resumos, etc) e informal (memorandos, conversas diretas, etc.);

- vertical (para cima e para baixo na organização) e horizontal (entre pares e organizações parceiras).

Negociação: discutir com outros no intuito de chegar a um acordo.

Solução de problemas: envolve definir o problema, diferenciando sintomas e causas, e a identificação das possíveis soluções.

Influência na organização: habilidade de "conseguir que as coisas sejam feitas", o que exige o entendimento das estruturas formais e informais de todas as organizações envolvidas, compreendendo também os mecanismos de política e poder.

O quadro 2 apresenta um relacionamento entre aplicações de narrativas de histórias (CAMILLE, WILLIAN, 2004; DENNING, 2005) e áreas descritas no PMBOK® (2004).
Quadro 2

Relacionamento entre propósitos de narrativas de histórias e áreas do PMBOK®.

\begin{tabular}{|c|c|c|}
\hline $\begin{array}{l}\text { Propósitos } \\
\text { da narrativa }\end{array}$ & $\begin{array}{c}\text { Área de } \\
\text { Especialização do } \\
\text { PMBOK@ } \\
\end{array}$ & $\begin{array}{l}\text { Aplicação/Habilidades } \\
\text { gerenciais do PMBOK® }\end{array}$ \\
\hline \multirow{3}{*}{$\begin{array}{l}\text { Exemplificar } \\
\text { a cultura } \\
\text { organizacional }\end{array}$} & $\begin{array}{l}\text { Habilidades } \\
\text { interpessoais. }\end{array}$ & $\begin{array}{l}\text { Liderança: estabelecer direção; } \\
\text { Liderança: motivação e inspiração; } \\
\text { Influenciar a organização; } \\
\text { Comunicação oral vertical e } \\
\text { horizontal }\end{array}$ \\
\hline & \begin{tabular}{|l|} 
Conhecimentos, \\
normas e \\
regulamentos da área \\
de aplicação. \\
\end{tabular} & $\begin{array}{l}\text { Conhecer normas, práticas e } \\
\text { procedimentos aceitos não } \\
\text { externalizados }\end{array}$ \\
\hline & \begin{tabular}{|l|} 
Entendimento do \\
ambiente do projeto.
\end{tabular} & $\begin{array}{l}\text { Compreender a cultura } \\
\text { organizacional pelas histórias }\end{array}$ \\
\hline $\begin{array}{l}\text { Modificar } \\
\text { e controlar } \\
\text { comportamento }\end{array}$ & $\begin{array}{l}\text { Habilidades } \\
\text { interpessoais }\end{array}$ & $\begin{array}{l}\text { Liderança: alinhar pessoas; } \\
\text { Negociação; } \\
\text { Influência na organização }\end{array}$ \\
\hline $\begin{array}{l}\text { Resolver } \\
\text { problemas e } \\
\text { tomar decisões } \\
\end{array}$ & $\begin{array}{l}\text { Habilidades } \\
\text { interpessoais }\end{array}$ & $\begin{array}{l}\text { Liderança: alinhar pessoas; } \\
\text { Solução de problemas; } \\
\text { Influếncia na organização }\end{array}$ \\
\hline $\begin{array}{l}\text { Gerenciar } \\
\text { mudanças }\end{array}$ & $\begin{array}{l}\text { Habilidades } \\
\text { interpessoais }\end{array}$ & $\begin{array}{l}\text { Liderança: estabelecer direção; } \\
\text { Liderança: alinhar pessoas; } \\
\text { Negociação; } \\
\text { Influência na organização }\end{array}$ \\
\hline $\begin{array}{l}\text { Planejamento } \\
\text { estratégico }\end{array}$ & \begin{tabular}{|l|} 
Habilidades \\
interpessoais
\end{tabular} & $\begin{array}{l}\text { Liderança: estabelecer direção; } \\
\text { Comunicação oral vertical }\end{array}$ \\
\hline $\begin{array}{l}\text { Melhorar a } \\
\text { imagem do líder }\end{array}$ & $\begin{array}{l}\text { Habilidades } \\
\text { interpessoais }\end{array}$ & Liderança: alinhar pessoas \\
\hline \multirow{2}{*}{$\begin{array}{l}\text { Transferir } \\
\text { conhecimento }\end{array}$} & $\begin{array}{l}\text { Habilidades } \\
\text { interpessoais }\end{array}$ & $\begin{array}{l}\text { Liderança: motivação e inspiração; } \\
\text { Comunicação oral vertical e } \\
\text { horizontal; }\end{array}$ \\
\hline & \begin{tabular}{|l|} 
Conhecimentos, \\
normas e \\
regulamentos da área \\
de aplicação \\
\end{tabular} & $\begin{array}{l}\text { Compartilhar normas, práticas } \\
\text { e procedimentos aceitos não } \\
\text { externalizados através de histórias }\end{array}$ \\
\hline \multirow{2}{*}{$\begin{array}{l}\text { Treinar futuros } \\
\text { líderes }\end{array}$} & $\begin{array}{l}\text { Habilidades } \\
\text { interpessoais }\end{array}$ & Comunicação oral vertical. \\
\hline & $\begin{array}{l}\text { Entendimento do } \\
\text { ambiente do projeto }\end{array}$ & $\begin{array}{l}\text { Compartilhar a cultura } \\
\text { organizacional através de histórias }\end{array}$ \\
\hline \multirow[t]{2}{*}{$\begin{array}{l}\text { Transmitir visão } \\
\text { de futuro }\end{array}$} & $\begin{array}{l}\text { Habilidades } \\
\text { interpessoais }\end{array}$ & $\begin{array}{l}\text { Liderança: estabelecer direção; } \\
\text { Liderança: motivação e inspiração; } \\
\text { Influenciar a organização; } \\
\text { Comunicação oral vertical e } \\
\text { horizontal }\end{array}$ \\
\hline & $\begin{array}{l}\text { Conhecimentos } \\
\text { e habilidades de } \\
\text { gerenciamento geral }\end{array}$ & $\begin{array}{l}\text { Ouvir as histórias organizacionais } \\
\text { para orientar o planejamento }\end{array}$ \\
\hline $\begin{array}{l}\text { Estimular a } \\
\text { colaboração }\end{array}$ & $\begin{array}{l}\text { Habilidades } \\
\text { interpessoais }\end{array}$ & $\begin{array}{l}\text { Liderança: motivação e inspiração; } \\
\text { Comunicação oral vertical e } \\
\text { horizontal }\end{array}$ \\
\hline $\begin{array}{l}\text { Silenciar } \\
\text { rumores }\end{array}$ & $\begin{array}{l}\text { Habilidades } \\
\text { interpessoais }\end{array}$ & $\begin{array}{l}\text { Liderança: estabelecer direção; } \\
\text { Liderança: motivação e inspiração; } \\
\text { Influenciar na organização; } \\
\text { Comunicação oral vertical e } \\
\text { horizontal. }\end{array}$ \\
\hline $\begin{array}{l}\text { Motivar a } \\
\text { equipe }\end{array}$ & $\begin{array}{l}\text { Habilidades } \\
\text { interpessoais }\end{array}$ & $\begin{array}{l}\text { Liderança: estabelecer direção; } \\
\text { Liderança: motivação e inspiração; } \\
\text { Influenciar a organização; } \\
\text { Comunicação oral vertical e } \\
\text { horizontal }\end{array}$ \\
\hline
\end{tabular}

Fontes: Camille e Willian (2004); Denning (2005); PMBOK®(2004). 


\section{Metodologia da pesquisa}

Para atender ao propósito deste trabalho, a pesquisa foi dividida em duas etapas: uma quantitativa e outra qualitativa. Para a pesquisa quantitativa, foi construído um questionário, que consta do Apêndice 1, que buscou obter as seguintes informações:

- qualificação do respondente: nome, e-mail, organização onde serve/trabalha, cargo ou função, formação acadêmica, faixa etária, tempo de experiência em gerenciamento de projetos;

c propósitos para as histórias narradas pelos gerentes;

- aprendizado sobre narrativas de histórias;

- fontes e histórias narradas pelos gerentes;

- audiências-alvo;

c áreas de conhecimento do PMBOK® e histórias narradas

pelos gerentes;

- compartilhamento de histórias.

O questionário foi enviado para técnicos envolvidos em projetos de TI, todos atuando em organizações militares $(\mathrm{OM})$ do Exército brasileiro sediadas na cidade de Brasília. Foram obtidas 39 respostas.

Após a análise dos resultados quantitativos e apoiado pelo referencial teórico, foi desenvolvido um método para aplicação de narrativas de histórias no gerenciamento de projetos de TI. Para testar o método, foram desenvolvidas 10 narrativas em apoio aos gerentes de uma das $\mathrm{OM}$, que já haviam participado da pesquisa quantitativa. A escolha da $\mathrm{OM}$ baseou-se na diversidade de projetos de TI desenvolvidos pela organização. O método constou dos seguintes passos: definição da situação existente; definição do propósito da história; definição da situação desejada; construção das histórias; seleção da história; agendamento (data, local, ouvintes e narrador); narrativa da história; verificação do que aconteceu.

\section{RESULTADOS E DISCUSSÃO}

\section{Resultados da pesquisa quantitativa}

Os dados foram obtidos pelo instrumento de coleta. A tabela 2 lista a diversidade de cargos e funções envolvidos no gerenciamento de projetos de TI para a população de 39 respondentes (n). O conhecimento de técnicas de gerenciamento não fica restrito apenas aos gerentes ou cargos de chefia: também os executores, como é o caso dos adjuntos ou analistas de sistemas, estão envolvidos em atividades de gerenciamento. Provavelmente a complexidade das atividades de projetos de TI implique o envolvimento de cargos com nível de execução em atividades gerenciais.

Buscando identificar a forma como as narrativas de histórias são empregadas no gerenciamento de projetos, os gerentes de projeto de uma organização de TI foram entrevistados, sendo coletadas
29 histórias que foram narradas no ambiente organizacional com propósitos gerenciais. Essas histórias fornecem indícios sobre a forma de aprendizado, fontes, propósitos e áreas de conhecimento em que foram utilizadas.

Tabela 2

Cargos ocupados pelos entrevistados $(n=39)$

\begin{tabular}{l|l|c|c}
\hline \multicolumn{1}{c|}{$\begin{array}{c}\text { Cargo } \\
\text { ocupado }\end{array}$} & \multicolumn{1}{c|}{ Descrição } & Amostras & $\%$ \\
\hline Adjunto & $\begin{array}{l}\text { Subordinado a um chefe de divisão ou } \\
\text { seção, auxilia nas atividades de chefia. }\end{array}$ & 09 & $23,08 \%$ \\
\hline $\begin{array}{l}\text { Gerente de } \\
\text { Sistema }\end{array}$ & $\begin{array}{l}\text { Responsável pela coordenação das } \\
\text { atividades necessárias para manter } \\
\text { um ou mais sistemas em operação. }\end{array}$ & 06 & $15,38 \%$ \\
\hline $\begin{array}{l}\text { Analista de } \\
\text { Sistemas }\end{array}$ & $\begin{array}{l}\text { Responsável pela especificação } \\
\text { de um produto de software, bem } \\
\text { como o acompanhamento de sua } \\
\text { implementacão. }\end{array}$ & 05 & $12,82 \%$ \\
\hline $\begin{array}{l}\text { Engenheiro } \\
\text { Denominação que abrange as diversas } \\
\text { especialidades envolvidas em projetos } \\
\text { de TI, como telecomunicações, } \\
\text { eletrônica ou mesmo engenharia de } \\
\text { software. }\end{array}$ & 05 & $12,82 \%$ \\
\hline $\begin{array}{l}\text { Gerente de } \\
\text { Projeto }\end{array}$ & $\begin{array}{l}\text { Responsável pelo andamento geral do } \\
\text { projeto. }\end{array}$ & 05 & $12,82 \%$ \\
\hline $\begin{array}{l}\text { Chefe de } \\
\text { Divisão }\end{array}$ & $\begin{array}{l}\text { Chefe de uma das divisões da } \\
\text { organização. }\end{array}$ & 03 & $7,70 \%$ \\
\hline $\begin{array}{l}\text { Administrador } \\
\text { de Dados }\end{array}$ & $\begin{array}{l}\text { Responsável pela integridade dos } \\
\text { dados e modelos da organização. }\end{array}$ & 02 & $5,13 \%$ \\
\hline $\begin{array}{l}\text { Chefe de } \\
\text { Secção }\end{array}$ & Chefe de um ramo da divisão. & 02 & $5,13 \%$ \\
\hline Assessor & $\begin{array}{l}\text { Cargo de assessoramento, com acesso } \\
\text { direto ao chefe da organização. }\end{array}$ & 01 & $2,56 \%$ \\
\hline $\begin{array}{l}\text { Gestor de } \\
\text { Sistemas }\end{array}$ & $\begin{array}{l}\text { Responsável pela gestão dos sistemas } \\
\text { da organização. }\end{array}$ & 01 & $2,56 \%$ \\
\hline
\end{tabular}

A tabela 3 foi obtida verificando-se, na ficha de entrevista, a forma como o gerente aprendeu a narrar histórias no ambiente organizacional. Vinte e sete respondentes declararam empregar narrativas de forma intuitiva, enquanto apenas doze passaram por outro processo de aprendizagem. Estes resultados evidenciam que os gerentes utilizam narrativas de histórias de forma intuitiva, sem aprendizado formal.

Tabela 3

Aprendizado de narrativas de histórias

\begin{tabular}{l|c|c}
\hline \multicolumn{1}{c|}{ Forma de Aprendizado } & Amostras & $\%$ \\
\hline Não fui ensinado, narro histórias de forma intuitiva & 27 & $69,23 \%$ \\
\hline Em curso de gerenciamento & 4 & $10,26 \%$ \\
\hline Li em uma revista ou livro & 3 & $7,69 \%$ \\
\hline Aprendi observando outros gerentes & 3 & $7,69 \%$ \\
\hline Aprendi em conversa com amigos & 2 & $5,13 \%$ \\
\hline Não conto histórias & 0 & $0 \%$ \\
\hline Outra & 0 & $0 \%$ \\
\hline
\end{tabular}

A tabela 4 sintetiza as fontes de onde as narrativas dos gerentes foram obtidas. É possível observar que a fonte mais utilizada 
é a vivência do gerente, que obteve a maior média $(2,62)$. $\mathrm{O}$ destaque pode ser observado também na moda, que atingiu o grau 3 (muitas vezes) apenas para essa fonte.

Cabe ressaltar que alguns respondentes afirmaram que às vezes as histórias foram inventadas. $\mathrm{O}$ fato de terem sido fruto da imaginação não significa que sejam falsas ou antiéticas. Uma das histórias inventadas, por exemplo, criou a imagem de um trem em movimento e o associou com a organização, tentando transmitir uma visão de futuro; foi uma estratégia bem-sucedida de construção de uma imagem compartilhada.

\section{Tabela 4}

\section{Fontes e histórias narradas pelos gerentes}

\begin{tabular}{|c|c|c|c|c|c|c|c|c|}
\hline \multirow[b]{2}{*}{$\begin{array}{l}\text { Fonte da } \\
\text { narrativa }\end{array}$} & \multicolumn{5}{|c|}{ Distribuição das respostas - (casos) e \% } & \multirow[b]{2}{*}{ 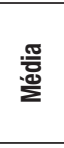 } & \multirow[b]{2}{*}{ 음 } & \multirow[b]{2}{*}{ 퐁 } \\
\hline & $\begin{array}{c}0 \\
\text { Nunca }\end{array}$ & \begin{tabular}{|c|}
1 \\
Poucas \\
vezes \\
\end{tabular} & $\begin{array}{c}2 \\
\text { Várias } \\
\text { vezes }\end{array}$ & \begin{tabular}{|c|}
3 \\
Muitas \\
vezes \\
\end{tabular} & $\begin{array}{c}4 \\
\text { Sempre }\end{array}$ & & & \\
\hline $\begin{array}{l}\text { Experiências } \\
\text { que vivi }\end{array}$ & $\begin{array}{l}(00) \\
00 \%\end{array}$ & $\begin{array}{c}(03) \\
7,69 \%\end{array}$ & $\begin{array}{c}(15) \\
38,46 \%\end{array}$ & $\begin{array}{c}(15) \\
38,46 \%\end{array}$ & $\begin{array}{c}(06) \\
15,38 \%\end{array}$ & 2,62 & 0,85 & 3 \\
\hline $\begin{array}{l}\text { Fábulas } \\
\text { populares }\end{array}$ & $\begin{array}{c}(10) \\
25,64 \%\end{array}$ & $\begin{array}{c}(21) \\
53,85 \%\end{array}$ & $\begin{array}{c}(06) \\
15,38 \%\end{array}$ & $\begin{array}{c}(02) \\
5,13 \%\end{array}$ & $\begin{array}{l}(00) \\
00 \%\end{array}$ & 1,00 & 0,79 & 1 \\
\hline Música & $\begin{array}{c}(26) \\
66,67 \%\end{array}$ & $\begin{array}{c}(10) \\
25,64 \%\end{array}$ & $\begin{array}{c}(03) \\
7,69 \%\end{array}$ & $\begin{array}{l}(00) \\
00 \%\end{array}$ & $\begin{array}{l}(00) \\
00 \%\end{array}$ & 0,41 & 0,64 & 0 \\
\hline $\begin{array}{l}\text { Livros, } \\
\text { revistas ou } \\
\text { jornais }\end{array}$ & $\begin{array}{c}(01) \\
2,56 \%\end{array}$ & $\begin{array}{c}(10) \\
25,64 \%\end{array}$ & $\begin{array}{c}(18) \\
46,15 \%\end{array}$ & $\begin{array}{c}(10) \\
25,64 \%\end{array}$ & $\begin{array}{l}(00) \\
00 \%\end{array}$ & 1,95 & 0,79 & 2 \\
\hline $\begin{array}{l}\text { Televisão: } \\
\text { novelas, } \\
\text { filmes, } \\
\text { telejornais }\end{array}$ & $\begin{array}{c}(05) \\
12,82 \%\end{array}$ & $\begin{array}{c}(16) \\
41,03 \%\end{array}$ & $\begin{array}{c}(10) \\
25,64 \%\end{array}$ & $\begin{array}{c}(07) \\
17,95 \%\end{array}$ & $\begin{array}{c}(01) \\
2,56 \%\end{array}$ & 1,56 & 1,02 & 1 \\
\hline $\begin{array}{l}\text { Conversas } \\
\text { com amigos } \\
\text { de outras } \\
\text { organiza- } \\
\text { ções }\end{array}$ & $\begin{array}{l}(00) \\
00 \%\end{array}$ & $\begin{array}{c}(10) \\
25,64 \%\end{array}$ & $\begin{array}{c}(19) \\
48,72 \%\end{array}$ & $\begin{array}{c}(08) \\
20,51 \%\end{array}$ & $\begin{array}{c}(02) \\
5,13 \%\end{array}$ & 2,05 & 0,83 & 2 \\
\hline $\begin{array}{l}\text { Procuro } \\
\text { histórias na } \\
\text { minha orga- } \\
\text { nização }\end{array}$ & $\begin{array}{c}(05) \\
12,82 \%\end{array}$ & $\begin{array}{c}(13) \\
33,33 \%\end{array}$ & $\begin{array}{c}(17) \\
43,60 \%\end{array}$ & $\begin{array}{c}(03) \\
7,69 \%\end{array}$ & $\begin{array}{c}(01) \\
2,56 \%\end{array}$ & 1,54 & 0,91 & 2 \\
\hline $\begin{array}{l}\text { Sites na } \\
\text { Internet }\end{array}$ & $\begin{array}{c}(04) \\
10,26 \%\end{array}$ & $\begin{array}{c}(16) \\
41,03 \%\end{array}$ & $\begin{array}{c}(15) \\
38,46 \%\end{array}$ & $\begin{array}{c}(04) \\
10,26 \%\end{array}$ & $\begin{array}{l}(00) \\
00 \%\end{array}$ & 1,49 & 0,82 & 1 \\
\hline E-mail & $\begin{array}{c}(06) \\
15,38 \%\end{array}$ & $\begin{array}{c}(23) \\
58,97 \%\end{array}$ & $\begin{array}{c}(09) \\
23,08 \%\end{array}$ & $\begin{array}{c}(01) \\
2,56 \%\end{array}$ & $\begin{array}{l}(00) \\
00 \%\end{array}$ & 1,13 & 0,70 & 1 \\
\hline $\begin{array}{l}\text { Lendas } \\
\text { organizacio- } \\
\text { nais } \\
\end{array}$ & $\begin{array}{c}(10) \\
25,64 \%\end{array}$ & $\begin{array}{c}(24) \\
57,14 \%\end{array}$ & $\begin{array}{c}(04) \\
10,26 \%\end{array}$ & $\begin{array}{c}(01) \\
2,56 \%\end{array}$ & $\begin{array}{l}(00) \\
00 \%\end{array}$ & 0,90 & 0,68 & 1 \\
\hline Eu invento & $\begin{array}{c}(23) \\
58,97 \%\end{array}$ & $\begin{array}{c}(13) \\
33,33 \%\end{array}$ & $\begin{array}{c}(03) \\
7,69 \%\end{array}$ & $\begin{array}{l}(00) \\
00 \%\end{array}$ & $\begin{array}{l}(00) \\
00 \%\end{array}$ & 0,49 & 0,64 & 0 \\
\hline Outra & $\begin{array}{l}(00) \\
00 \%\end{array}$ & $\begin{array}{l}(00) \\
00 \%\end{array}$ & $\begin{array}{c}(01) \\
2,56 \%\end{array}$ & $\begin{array}{c}(01) \\
2,56 \%\end{array}$ & $\begin{array}{c}(01) \\
2,56 \%\end{array}$ & 3 & 1,00 & - \\
\hline $\begin{array}{l}\text { Geral - } \\
\text { Fonte da } \\
\text { Narrativa }\end{array}$ & $\begin{array}{c}(90) \\
20,83 \%\end{array}$ & $\begin{array}{c}(159) \\
36,81 \%\end{array}$ & $\begin{array}{c}(120) \\
27,78 \%\end{array}$ & $\begin{array}{c}(52) \\
12,04 \%\end{array}$ & $\begin{array}{c}(11) \\
2,55 \%\end{array}$ & 1,39 & 1,02 & 1 \\
\hline
\end{tabular}

A tabela 5 relaciona vários propósitos de narrativas identificados na literatura (CAMILLE, WILLIAN, 2004; DENNING, 2005; BOYCE apud TAYLOR et al. 2002) e apresenta a freqüência das respostas obtidas. Outros propósitos citados foram relacionamento interpessoal; criticar processos organizacionais; estimular a fé em Deus; ilustrar estudo de caso.

Ao analisar a média das respostas, é possível identificar os propósitos mais freqüentes de narrativas, que são estimular a colaboração e motivar a equipe. Transferir conhecimento também obteve boa média, mas melhorar a imagem e treinar futuros líderes são os propósitos menos utilizados.

\section{Tabela 5}

\section{Propósitos para as histórias narradas pelos gerentes}

\begin{tabular}{|c|c|c|c|c|c|c|c|c|}
\hline \multirow[b]{2}{*}{$\begin{array}{l}\text { Propósito da } \\
\text { narrativa }\end{array}$} & \multicolumn{5}{|c|}{ Distribuição das respostas - (casos) e \% } & \multirow[b]{2}{*}{ : } & \multirow[b]{2}{*}{ 음 } & \multirow[b]{2}{*}{ 풍 } \\
\hline & $\begin{array}{c}0 \\
\text { Nunca }\end{array}$ & $\begin{array}{c}1 \\
\text { Poucas } \\
\text { vezes }\end{array}$ & $\begin{array}{c}2 \\
\text { Várias } \\
\text { vezes }\end{array}$ & \begin{tabular}{|c|}
3 \\
Muitas \\
vezes
\end{tabular} & \begin{tabular}{c|}
4 \\
Sempre
\end{tabular} & & & \\
\hline $\begin{array}{l}\text { Exemplificar a } \\
\text { cultura da organi- } \\
\text { zação }\end{array}$ & $\begin{array}{c}(03) \\
7,69 \%\end{array}$ & $\left|\begin{array}{c}(11) \\
28,21 \%\end{array}\right|$ & $\begin{array}{c}(17) \\
43,59 \%\end{array}$ & $\begin{array}{c}(07) \\
17,95 \%\end{array}$ & \begin{tabular}{c|}
$(01)$ \\
$2,56 \%$
\end{tabular} & 1,82 & 0,92 & 2 \\
\hline $\begin{array}{l}\text { Modificar e } \\
\text { controlar compor- } \\
\text { tamentos }\end{array}$ & $\begin{array}{c}(01) \\
2,56 \%\end{array}$ & $\left|\begin{array}{c}(11) \\
28,21 \%\end{array}\right|$ & $\begin{array}{c}(16) \\
41,03 \%\end{array}$ & $\begin{array}{c}(09) \\
23,08 \%\end{array}$ & $\begin{array}{c}(02) \\
5,13 \%\end{array}$ & 2,03 & 0,91 & 2 \\
\hline $\begin{array}{l}\text { Resolver proble- } \\
\text { mas }\end{array}$ & $\begin{array}{c}(01) \\
2,56 \%\end{array}$ & $\left|\begin{array}{c}(11) \\
28,21 \%\end{array}\right|$ & $\begin{array}{c}(18) \\
46,15 \%\end{array}$ & $\begin{array}{c}(07) \\
17,95 \%\end{array}$ & $\begin{array}{c}(02) \\
5,13 \%\end{array}$ & 1,97 & 0,89 & 2 \\
\hline $\begin{array}{l}\text { Gerenciar mu- } \\
\text { danças }\end{array}$ & $\begin{array}{c}(03) \\
7,69 \%\end{array}$ & $\begin{array}{c}(13) \\
33,33 \%\end{array}$ & $\begin{array}{c}(16) \\
41,03 \%\end{array}$ & \begin{tabular}{c|}
$(07)$ \\
$17,95 \%$
\end{tabular} & $\begin{array}{l}(00) \\
0 \%\end{array}$ & 1,71 & 0,86 & 2 \\
\hline $\begin{array}{l}\text { Estimular a criati- } \\
\text { vidade/inovação }\end{array}$ & $\begin{array}{c}(01) \\
2,56 \%\end{array}$ & $\mid \begin{array}{c}(10) \\
25,64 \%\end{array}$ & $\begin{array}{c}(17) \\
43,59 \%\end{array}$ & $\begin{array}{c}(08) \\
20,51 \%\end{array}$ & $\begin{array}{c}(03) \\
7,69 \%\end{array}$ & 2,05 & 0,94 & 2 \\
\hline $\begin{array}{l}\text { Melhorar a sua } \\
\text { imagem, comuni- } \\
\text { car quem você é }\end{array}$ & $\begin{array}{c}(10) \\
25,64 \%\end{array}$ & $\mid \begin{array}{c}(20) \\
51,28 \%\end{array}$ & $\begin{array}{c}(06) \\
15,38 \%\end{array}$ & $\begin{array}{c}(02) \\
5,13 \%\end{array}$ & $\begin{array}{c}(01) \\
2,56 \%\end{array}$ & 1,08 & 0,93 & 1 \\
\hline $\begin{array}{l}\text { Transferir conheci- } \\
\text { mento }\end{array}$ & $\begin{array}{c}(03) \\
7,69 \%\end{array}$ & $\begin{array}{c}(07) \\
17,95 \%\end{array} \mid$ & $\begin{array}{c}(16) \\
41,03 \%\end{array}$ & $\begin{array}{c}(07) \\
17,95 \%\end{array}$ & \begin{tabular}{|c|}
$(06)$ \\
$15,38 \%$
\end{tabular} & 2,21 & 1,17 & 2 \\
\hline $\begin{array}{l}\text { Treinar futuros } \\
\text { líderes }\end{array}$ & $\begin{array}{c}(09) \\
23,08 \%\end{array}$ & $\begin{array}{c}(14) \\
35,90 \%\end{array}$ & $\begin{array}{c}(07) \\
17,95 \%\end{array}$ & $\begin{array}{c}(07) \\
17,95 \%\end{array}$ & $\begin{array}{c}(02) \\
5,13 \%\end{array}$ & 1,47 & 1,19 & 1 \\
\hline $\begin{array}{l}\text { Transmitir sua } \\
\text { visão de futuro }\end{array}$ & $\begin{array}{c}(01) \\
2,56 \%\end{array}$ & \begin{tabular}{|c|}
$(09)$ \\
$23,08 \%$
\end{tabular} & $\begin{array}{c}(18) \\
46,15 \%\end{array}$ & \begin{tabular}{|c|}
$(10)$ \\
$25,64 \%$
\end{tabular} & $\begin{array}{c}(01) \\
2,56 \%\end{array}$ & 2,03 & 0,84 & 2 \\
\hline $\begin{array}{l}\text { Estimular a } \\
\text { colaboração }\end{array}$ & $\begin{array}{l}(00) \\
0 \%\end{array}$ & $\left|\begin{array}{c}(08) \\
20,51 \%\end{array}\right|$ & $\begin{array}{c}(16) \\
41,03 \%\end{array}$ & $\left|\begin{array}{c|}(11) \\
28,21 \%\end{array}\right|$ & \begin{tabular}{c|}
$(04)$ \\
$10,26 \%$
\end{tabular} & 2,29 & 0,92 & 2 \\
\hline Silenciar rumores & $\begin{array}{c}(07) \\
17,95 \%\end{array}$ & $\begin{array}{c}(20) \\
51,28 \%\end{array}$ & $\begin{array}{c}(08) \\
20,51 \%\end{array}$ & \begin{tabular}{|c|}
$(03)$ \\
$7,69 \%$
\end{tabular} & $\begin{array}{c}(01) \\
2,56 \%\end{array}$ & 1,24 & 0,94 & 1 \\
\hline Motivar a equipe & $\begin{array}{l}(00) \\
0 \%\end{array}$ & $\begin{array}{c}(09) \\
23,08 \%\end{array} \mid$ & $\begin{array}{c}(16) \\
41,03 \%\end{array}$ & \begin{tabular}{|c|}
$(08)$ \\
$20,51 \%$
\end{tabular} \mid & \begin{tabular}{|c|}
$(06)$ \\
$15,38 \%$
\end{tabular} & 2,29 & 1,00 & 2 \\
\hline Outra & $\begin{array}{l}(00) \\
0 \%\end{array}$ & $\begin{array}{l}(00) \\
0 \%\end{array}$ & $\begin{array}{l}(00) \\
0 \%\end{array}$ & $\begin{array}{c}(03) \\
7,69 \%\end{array}$ & $\begin{array}{c}(01) \\
2,56 \%\end{array}$ & 0,35 & 1,02 & - \\
\hline $\begin{array}{l}\text { Geral - Freqüência } \\
\text { com que narra } \\
\text { histórias }\end{array}$ & $\begin{array}{c}(39) \\
8,26 \%\end{array}$ & \begin{tabular}{|c|}
$(143)$ \\
$30,30 \%$
\end{tabular} & $\begin{array}{c}(171) \\
36,23 \%\end{array}$ & $\begin{array}{c}(89) \\
18,86 \%\end{array}$ & $\begin{array}{c}(30) \\
6,36 \%\end{array}$ & 1,84 & 1,03 & 2 \\
\hline
\end{tabular}


Algumas histórias foram enquadradas em mais de um propósito, o que demonstra sua capacidade de lidar com a complexidade da realidade. A história narrada intencionalmente para atingir um propósito pode surtir efeitos imprevistos, como cumprir outro propósito não previsto, mas até útil ou necessário.

Investigando para quem o gerente narra suas histórias, pode-se compreender o uso de narrativas de histórias no gerenciamento de projetos. A tabela 6 mostra que subordinados, companheiros (pares) e superiores são as audiências mais freqüentes. Os subordinados são o alvo mais comum, com média de 2,51 e moda 3 (muitas vezes).

Tabela 6

\section{Audiências-alvo}

\begin{tabular}{|c|c|c|c|c|c|c|c|c|}
\hline \multirow[b]{2}{*}{ Audiência-alvo } & \multicolumn{5}{|c|}{ Distribuiç̧ão das respostas - (casos) e \% } & \multirow[b]{2}{*}{ 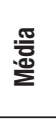 } & \multirow[b]{2}{*}{ 은 } & \multirow[b]{2}{*}{ 플 } \\
\hline & \begin{tabular}{|c|}
0 \\
Nunca
\end{tabular} & \begin{tabular}{|c|}
1 \\
Poucas \\
vezes \\
\end{tabular} & $\begin{array}{c}2 \\
\text { Várias } \\
\text { vezes }\end{array}$ & \begin{tabular}{|c|}
3 \\
Muitas \\
vezes \\
\end{tabular} & $\begin{array}{c}4 \\
\text { Sempre } \\
\end{array}$ & & & \\
\hline iborc & $\begin{array}{l}(00) \\
00 \%\end{array}$ & $\begin{array}{c}(04) \\
10,26 \%\end{array}$ & $\begin{array}{c}(15) \\
38,46 \%\end{array}$ & $\begin{array}{c}(16) \\
41,03 \%\end{array}$ & $\begin{array}{c}(04) \\
10,26 \%\end{array}$ & 2,51 & 0,82 & 3 \\
\hline Client & $\begin{array}{c}(03) \\
7,69 \%\end{array}$ & $\begin{array}{c}(18) \\
46,15 \%\end{array}$ & $\begin{array}{c}(15) \\
38,46 \%\end{array}$ & $\begin{array}{l}(03) \\
7,69\end{array}$ & $\begin{array}{l}(00) \\
00 \%\end{array}$ & 1,46 & 0,76 & 1 \\
\hline$s$ & $\begin{array}{c}(09) \\
23,08 \%\end{array}$ & $\begin{array}{c}(17) \\
43,59 \%\end{array}$ & $\begin{array}{c}(12) \\
30,77 \%\end{array}$ & $\begin{array}{c}(01) \\
2,56 \%\end{array}$ & $\begin{array}{l}(00) \\
00 \%\end{array}$ & 1,13 & 0,80 & 1 \\
\hline$s$ & $\begin{array}{l}(00) \\
00 \%\end{array}$ & $\begin{array}{c}(05) \\
12,82 \%\end{array}$ & $\begin{array}{c}(18) \\
46,15 \%\end{array}$ & $\begin{array}{c}(14) \\
35,90 \%\end{array}$ & $\begin{array}{c}(02) \\
5,13 \%\end{array}$ & 2,33 & 0,77 & 2 \\
\hline Superiores & $2,56 \%$ & $\begin{array}{c}(19) \\
48,72 \%\end{array}$ & $\begin{array}{c}(13) \\
33,33 \%\end{array}$ & $\begin{array}{c}(05) \\
12,82 \%\end{array}$ & $\begin{array}{c}(01) \\
2,56 \%\end{array}$ & 2,33 & 0,84 & 1 \\
\hline $\begin{array}{l}\text { Workshops na } \\
\text { minha organização }\end{array}$ & $\begin{array}{c}(17) \\
43,59 \%\end{array}$ & $\begin{array}{c}(15) \\
38,46 \%\end{array}$ & $\begin{array}{c}(06) \\
15,38 \%\end{array}$ & $\begin{array}{c}(01) \\
2,56 \%\end{array}$ & $\begin{array}{l}(00) \\
00 \%\end{array}$ & 0,77 & 0,81 & 0 \\
\hline $\begin{array}{l}\text { Workshops fora da } \\
\text { minha organização }\end{array}$ & $\begin{array}{c}(12) \\
30,77 \%\end{array}$ & $\begin{array}{c}(16) \\
41,03 \%\end{array}$ & $\begin{array}{c}(09) \\
23,08 \%\end{array}$ & $\begin{array}{c}(01) \\
2,56 \%\end{array}$ & $\begin{array}{c}(01) \\
2,56 \%\end{array}$ & 1,05 & 0,94 & 1 \\
\hline $\begin{array}{l}\text { Conferências/ } \\
\text { palestras na minha } \\
\text { organização }\end{array}$ & $\begin{array}{c}(06) \\
15,38 \%\end{array}$ & $\begin{array}{c}(22) \\
56,41 \%\end{array}$ & $\begin{array}{c}(07) \\
17,95 \%\end{array}$ & $\begin{array}{c}(03) \\
7,69 \%\end{array}$ & $\begin{array}{l}(01) \\
2,56 \%\end{array}$ & 1,26 & 0,91 & 1 \\
\hline $\begin{array}{l}\text { Conferências/ } \\
\text { palestras fora da } \\
\text { minha organização }\end{array}$ & $\begin{array}{c}(06) \\
15,38 \%\end{array}$ & $\begin{array}{c}(18) \\
46,15 \%\end{array}$ & $\begin{array}{c}(10) \\
25,64 \%\end{array}$ & $\begin{array}{c}(04) \\
10,26 \%\end{array}$ & $\begin{array}{c}(01) \\
2,56 \%\end{array}$ & 1,38 & 0,96 & 1 \\
\hline Outra & $\begin{array}{l}(00) \\
00 \%\end{array}$ & $\begin{array}{l}(00) \\
00 \%\end{array}$ & $\begin{array}{l}(00) \\
00 \%\end{array}$ & $\begin{array}{l}(00) \\
00 \%\end{array}$ & $\begin{array}{l}(00) \\
00 \%\end{array}$ & 0,00 & - & \\
\hline $\begin{array}{l}\text { Geral - Audiên- } \\
\text { cia da } \\
\text { Narrativa }\end{array}$ & $\begin{array}{c}(73) \\
16,55 \%\end{array}$ & \begin{tabular}{|c|}
$(150)$ \\
$34,01 \%$
\end{tabular} & $\begin{array}{c}(126) \\
28,57 \%\end{array}$ & $\begin{array}{c}(72) \\
16,32 \%\end{array}$ & $\begin{array}{c}(21) \\
4,53 \%\end{array}$ & 1,50 & 1,00 & 1 \\
\hline
\end{tabular}

O gerente encara os subordinados como seu principal recurso, e o mais difícil de ser administrado. Deve resolver ou prevenir problemas das mais diversas ordens, e para isso a narrativa de histórias é uma ferramenta poderosa. Os companheiros são outro alvo comum, provavelmente no compartilhamento de conhecimentos e experiências. Várias organizações já descobriram que essa troca de informações é salutar para a organização e passaram a estimular o encontro de pessoas para a socialização de conhecimentos (WENGER, 2002, p. 1-12).

Os superiores também possuem média alta, de 2,33. Isso indica que o uso de narrativas na comunicação com chefes é freqüente, seja para melhorar a imagem, transferir conhecimento, transmitir visão de futuro ou silenciar rumores.
A tabela 7 lista as áreas de conhecimento do PMBOK® (2004) e o nível de adequação das narrativas, no julgamento dos respondentes. A área mais adequada, obtendo média 3,31 e moda 4 ("totalmente adequado"), foi a de gerenciamento de recursos humanos. Em seguida, obtendo moda 3 (muito adequado), aparecem gerenciamento de integração, gerenciamento de tempo, gerenciamento de comunicação e gerenciamento de risco.

Nenhuma área de conhecimento obteve moda inferior a dois ("adequado"), indicando que os gerentes consideram as narrativas de histórias adequadas a todas as áreas de conhecimento do $\mathrm{PMBOK}$ ®. A área que obteve menor média foi gerenciamento de aquisições $(2,35)$.

\section{Tabela 7}

\section{Áreas de conhecimento do PMBOK® e histórias narradas pelos gerentes}

\begin{tabular}{|c|c|c|c|c|c|c|c|c|c|}
\hline \multirow[b]{2}{*}{$\begin{array}{l}\text { Área de } \\
\text { conheci- } \\
\text { mento }\end{array}$} & \multicolumn{6}{|c|}{ Distribuição das respostas - (casos) e \% } & \multirow[b]{2}{*}{ 墨 } & \multirow[b]{2}{*}{ 음 } & \multirow[b]{2}{*}{ 采 } \\
\hline & Não sei & $\begin{array}{c}0 \\
\text { Inade- } \\
\text { quado }\end{array}$ & $\begin{array}{c}1 \\
\text { Pouco } \\
\text { adequado }\end{array}$ & $\begin{array}{c}2 \\
\text { Adequa- } \\
\text { do }\end{array}$ & $\begin{array}{c}3 \\
\text { Muito } \\
\text { adequado }\end{array}$ & \begin{tabular}{|c|}
4 \\
Totalmente \\
adequado
\end{tabular} & & & \\
\hline $\begin{array}{l}a- \\
e \\
\tilde{e}\end{array}$ & $\begin{array}{c}(03) \\
7,69 \%\end{array}$ & $\begin{array}{c}(03) \\
7,69 \%\end{array}$ & $\begin{array}{c}(03) \\
7,69 \%\end{array}$ & $\begin{array}{l}(111) \\
8,21 \%\end{array}$ & $\begin{array}{c}(12) \\
30,77 \%\end{array}$ & $\begin{array}{c}(07) \\
17,95 \%\end{array}$ & 2,47 & 1,16 & 3, \\
\hline $\begin{array}{l}\text { rencia- } \\
\text { ento de } \\
\text { copo }\end{array}$ & $\begin{array}{c}(04) \\
10,26 \%\end{array}$ & $\begin{array}{c}(02) \\
5,13 \%\end{array}$ & $\begin{array}{c}(03) \\
7,69 \%\end{array}$ & $\begin{array}{c}(13) \\
33,33 \%\end{array}$ & $\begin{array}{c}(10) \\
25,64 \%\end{array}$ & $\begin{array}{c}(07) \\
17,95 \%\end{array}$ & 2,49 & 1,09 & 2,0 \\
\hline $\begin{array}{l}\text { erencia- } \\
\text { nento de } \\
\text { empo }\end{array}$ & $\begin{array}{c}(04) \\
10,26 \%\end{array}$ & $\begin{array}{c}(01) \\
2,56 \%\end{array}$ & $\begin{array}{c}(02) \\
5,13 \%\end{array}$ & $\begin{array}{c}(11) \\
28,21\end{array}$ & $\begin{array}{c}(12) \\
30,77 \%\end{array}$ & $\begin{array}{c}(09) \\
23,08 \%\end{array}$ & 2,74 & 1,01 & 3,0 \\
\hline $\begin{array}{l}\text { Gerenc } \\
\text { mento } \\
\text { custos }\end{array}$ & $\begin{array}{c}(04) \\
10,26 \%\end{array}$ & $\begin{array}{c}(01) \\
2,56 \%\end{array}$ & $\begin{array}{c}(05) \\
12,82 \%\end{array}$ & $\begin{array}{c}(13) \\
33,33 \%\end{array}$ & $\begin{array}{c}(08) \\
20,51 \%\end{array}$ & $\begin{array}{c}(08) \\
20,51 \%\end{array}$ & 2,49 & 1,09 & 2,0 \\
\hline $\begin{array}{l}\text { Geren } \\
\text { mento } \\
\text { qualid }\end{array}$ & $\begin{array}{c}(05) \\
12,82 \%\end{array}$ & $\begin{array}{l}(00) \\
00 \%\end{array}$ & $\begin{array}{c}(01) \\
2,56 \%\end{array}$ & $\begin{array}{c}(14) \\
35,90 \%\end{array}$ & $\begin{array}{c}(12) \\
30,77 \%\end{array}$ & $\begin{array}{c}(07) \\
17,95 \%\end{array}$ & 2,74 & 0,83 & 2,0 \\
\hline $\begin{array}{l}\text { Gerencia- } \\
\text { mento de } \\
\text { RH }\end{array}$ & $\begin{array}{c}(03) \\
7,69 \%\end{array}$ & $\begin{array}{l}(00) \\
00 \%\end{array}$ & $\begin{array}{c}(01) \\
2,56 \%\end{array}$ & $\begin{array}{c}(05) \\
12,82 \%\end{array}$ & $\begin{array}{c}(12) \\
30,77 \%\end{array}$ & $\begin{array}{c}(18) \\
46,15 \%\end{array}$ & 3,31 & 0,82 & 4,0 \\
\hline $\begin{array}{l}\text { Gerencia- } \\
\text { mento de } \\
\text { comunica- } \\
\text { cão }\end{array}$ & $\begin{array}{c}(03) \\
7,69 \%\end{array}$ & $\begin{array}{c}(01) \\
2,56 \%\end{array}$ & $\begin{array}{c}(04) \\
10,26 \%\end{array}$ & $\begin{array}{c}(08) \\
20,51 \%\end{array}$ & $\begin{array}{c}(13) \\
33,33 \%\end{array}$ & $\begin{array}{c}(10) \\
25,64 \%\end{array}$ & 2,75 & 1,08 & 3,0 \\
\hline $\begin{array}{l}\text { Gerencia- } \\
\text { mento de } \\
\text { riscos }\end{array}$ & $\begin{array}{c}(03) \\
7,69 \%\end{array}$ & $\begin{array}{l}(00) \\
00 \%\end{array}$ & $\begin{array}{c}(02) \\
5,13 \%\end{array}$ & $\begin{array}{c}(12) \\
30,77 \%\end{array}$ & $\begin{array}{c}(16) \\
41,03 \%\end{array}$ & $\begin{array}{c}(06) \\
15,38 \%\end{array}$ & 2,72 & 0,82 & 3,0 \\
\hline $\begin{array}{l}\text { Gerencia- } \\
\text { mento de } \\
\text { aquisiçõos }\end{array}$ & $\begin{array}{c}(05) \\
12,82 \%\end{array}$ & $\begin{array}{l}(00) \\
00 \%\end{array}$ & $\begin{array}{c}(05) \\
12,82 \%\end{array}$ & $\begin{array}{c}(16) \\
41,03 \%\end{array}$ & $\begin{array}{c}(09) \\
23,08 \%\end{array}$ & $\begin{array}{c}(04) \\
10,26 \%\end{array}$ & 2,35 & 0,91 & 2,0 \\
\hline \begin{tabular}{|l} 
Geral - \\
Área de \\
conheci- \\
mento \\
\end{tabular} & $\begin{array}{c}(38) \\
9,69 \%\end{array}$ & $\begin{array}{c}(08) \\
2,28 \%\end{array}$ & $\begin{array}{c}(33) \\
7,41 \%\end{array}$ & $\begin{array}{c}(124) \\
29,34 \%\end{array}$ & $\begin{array}{c}(122) \\
29,63 \%\end{array}$ & $\begin{array}{c}(100) \\
21,65 \%\end{array}$ & 2,68 & 1,01 & 3,0 \\
\hline
\end{tabular}

Apenas 9,69\% dos respondentes declararam duvidar se as narrativas seriam adequadas a determinada área de conhecimento. Três pessoas declararam dúvidas em todas as áreas por desconhecimento do $\mathrm{PMBOK} \AA$.

Na média geral, a técnica de narrativas de histórias obteve média de 2,68\% e moda 3 (muito adequado), confirmando que os respondentes consideram seu uso aderente aos processos prescritos pelo $\mathrm{PMBOK}$. 
A coluna "não sei" revela incapacidade de opinar sobre a aplicabilidade das narrativas em determinada área de conhecimento e, por isso, foi desconsiderada para cálculo da média, desvio padrão e moda da tabela 7.

\section{DESENVOLVIMENTO DO PROCESSO PARA USO DE NARRATIVAS EM PROJETOS}

A literatura foi suficiente para identificar para quais propósitos torna-se conveniente empregar histórias, mas faltava um processo que orientasse o seu emprego. Provavelmente não houve, até então, preocupação dos autores em elaborar um processo, porque a técnica de histórias fundamenta-se no contexto da narrativa, abstraindo registros por escrito. Entretanto, a presente pesquisa, em sua segunda fase, buscou elaborar uma proposta de emprego de narrativa de histórias no gerenciamento de projetos de TI.

A figura 3 ilustra o processo desenhado para a aplicação da técnica de narrativas de histórias. Espera-se que este modelo facilite a compreensão sobre como empregar a técnica de narrativas na resolução de problemas ou combate a riscos de projetos a seu encargo. Cada caixa da figura consiste em uma atividade detalhada a seguir. O processo é cíclico, podendo ser executado várias vezes durante o projeto. Todavia, o ambiente deve estar sempre sendo monitorado pelo gerente.

\section{Monitoração do ambiente}

A nuvem ao centro indica que o gerente deve estar sempre atento ao ambiente, de forma a perceber os problemas que podem impedir o sucesso de seu projeto e saber a oportunidade adequada, bem como as pessoas que devem ouvir determinada narrativa. Qualquer mudança no ambiente deve ser percebida imediatamente, pois pode invalidar o planejamento de emprego de uma narrativa.

\section{Figura 3}

\section{Processo de emprego de narrativas}

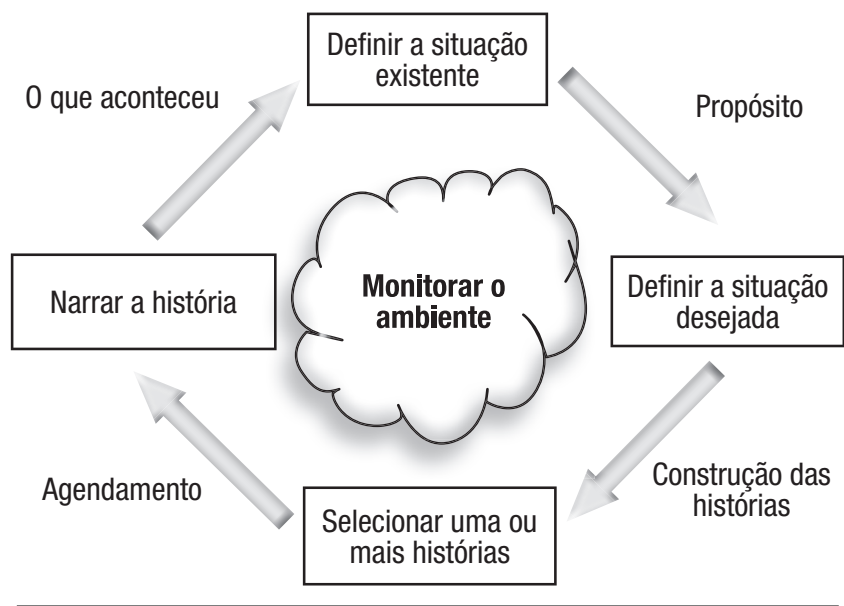

A monitoração permite que o gerente tome ciência da audiência e o contexto em que está envolvida. O conhecimento do contexto é imprescindível para o sucesso da narrativa, pois o gerente deve ter a capacidade de prever como os ouvintes interpretarão uma história, bem como a capacidade de contar a história certa no momento certo.

\section{Definição da situação existente}

A etapa de "definir a situação existente" baseia-se na pergunta: "qual é o problema?". O objetivo é auxiliar a externalização do contexto que deveria ser modificado. A situação existente define o diagnóstico de um contexto que, na percepção do gerente, esteja trazendo ou possa vir a trazer prejuízos ao projeto de TI. Por vezes, o gerente de TI se vê incapaz de resolver uma situação problemática devido à falta de habilidades interpessoais, pois possui formação essencialmente técnica.

\section{Definição da situação desejada}

"Definir a situação desejada" é a tarefa em que se define como seria o contexto adequado ao sucesso do projeto de TI. O gerente deve ser capaz de definir qual é a situação mais conveniente ao sucesso de seu projeto. A transição da situação existente para a situação desejada consiste no propósito, que é elemento importante na busca de uma história adequada.

A bibliografia cita os seguintes propósitos de emprego de narrativas (DENNING, 2005; BOYCE apud TAYLOR et al., 2002; CAMILLE; WILLIAN, 2004): comunicar uma idéia complexa e estimular uma ação; formar um grupo ou comunidade de trabalho; compartilhar informação e conhecimento; acalmar boatos e neutralizar fofocas negativas; comunicar quem você é; transmitir valores; sinalizar para as pessoas o futuro; expressar a experiência organizacional de membros e clientes; confirmar as experiências e significados compartilhados de membros e grupos dentro da organização; orientar e socializar novos membros; desenvolver, aprimorar e renovar o propósito defendido pelos membros; preparar um grupo para o planejamento, implementação de planos e tomada de decisão, alinhados com propósitos compartilhados; co-criação da visão e estratégia; exemplificar a cultura corporativa; modificar e controlar comportamento; resolver problemas e tomar decisões; gerenciar mudanças; planejar estratégias; melhorar a imagem do líder; transferir conhecimento; treinar futuros líderes.

\section{Construção e seleção das histórias}

Consciente do propósito, a próxima etapa consiste na tarefa mais difícil, ou seja, a construção de uma ou mais histórias que possam desencadear mudanças no ambiente, transpondo-o da situação existente para a desejada.

O gerente do projeto pode sugerir suas próprias histórias para cumprir o propósito almejado. Os dados coletados na pesquisa 
revelam que a vivência pessoal é a fonte mais empregada para levantamento de narrativas. Algumas vezes o gerente não se recordou de uma experiência pessoal adequada, e, então, a conversa com outros gerentes pode ser útil, pois os problemas a serem resolvidos freqüentemente já haviam ocorrido em outros projetos de TI.

Algumas histórias podem ser narradas várias vezes por diferentes gerentes, com propósitos semelhantes em projetos e audiências distintas. Esse fato indica que o compartilhamento de narrativas possui aplicabilidade na atividade gerencial, talvez por isso a participação em workshops e conferências seja importante para eles: é o local onde se reúnem para trocar histórias.

A Internet possui uma infinidade de histórias, mas nenhum instrumento de busca de acordo com o propósito. Qualquer busca traz muitas histórias, de forma que selecionar alguma que seja adequada ao contexto do projeto é como "procurar uma agulha no palheiro".

A etapa de selecionar histórias é complexa, pois exige compreensão do ambiente e um palpite sobre como a audiência irá interpretar a história. Essa habilidade é adquirida por meio do conhecimento do contexto e da audiência, mas mesmo assim não se pode ter certeza de como a história será interpretada.

A escolha de histórias de sucesso deve ser feita com cuidado, pois pode surtir efeito inverso ao esperado (DENNING, 2004a). Em contrapartida, as histórias negativas de fracassos anteriores instruem para o sucesso no presente (STAVRI, 2003). O fracasso seria um conceito relativo, pois analisado em um contexto mais amplo no tempo pode ser um passo para o sucesso. As histórias de projetos malsucedidos são importantes no processo de aprendizagem organizacional, apesar de as pessoas não serem muito propícias a documentar suas falhas (SCHINDLER, 2003). Por isso, a organização deve estimular a produção de histórias tendo como fonte os problemas dos projetos, pois são muito úteis para ensinar o que não deve ser feito.

Taylor et al. (2002) investigaram por que algumas narrativas são mais efetivas do que outras, sendo que a estética da história pode ser selecionada segundo os seguintes aspectos: sentimento de significado: a intuição do ouvinte tende a acreditar na história; conectividade: a história desperta ressonância no ouvinte, que viveu experiência semelhante; apreciada por si mesma: a história é agradável e por isso aceita pelos ouvintes, que reduzem seus filtros críticos e possíveis questionamentos.

\section{Narrativa da(s) história(s)}

Após a seleção das histórias a serem narradas, deve ser programado um agendamento para cada uma delas, no qual constem os seguintes itens: data prevista para a narrativa; local onde se fará a narrativa; para que sejam instalados os equipamentos e feitos os ajustes necessários; especificação das pessoas que devem estar presentes à narrativa; definição da pessoa que fará a narrativa.

A etapa de "narrar a história" deve ser conduzida de forma natural. Não convém a uma história organizacional que o narrador faça uma performance, modificando seu tom de voz e comportamento usual. A narrativa deve ter credibilidade, e tudo deve ser verdadeiro, inclusive os gestos do narrador, que deve ter em mente que está simplesmente compartilhando um conhecimento com outros seres humanos. Se o ouvinte perceber alguma alteração no modo de ser de quem narra, a credibilidade da história provavelmente estará comprometida.

Esse é um aspecto peculiar das narrativas de histórias organizacionais, pois em outros contextos é usual modificar-se o tom de voz, a atitude e comportamento do narrador, que deve ser um showman. O importante é que a mensagem seja passada do narrador para a audiência, visando a alcançar uma percepção transformadora. O objetivo é que os participantes percebam o contexto de forma diferente do entendimento atual.

A história pode ser narrada em qualquer situação, seja numa reunião formal, num encontro informal ou numa palestra na organização. As histórias narradas na presente pesquisa foram contadas em exposições formais dos projetos em questão. A narrativa que aproveita uma reunião formal possui data e hora marcada, com possibilidade de preparar-se material, como slides e fotos, ou seja, o ambiente é controlável. A história narrada em situações informais acontece ad hoc, pois não admite preparação do ambiente, e a condução do ambiente para um contexto propício à narrativa pode caracterizar uma manipulação maniqueísta que compromete a sua credibilidade.

\section{Observando o que aconteceu}

O gerente deve observar no ambiente o que aconteceu após a narrativa da história, verificando se a situação evoluiu para a desejada. Caso isso tenha acontecido, identificar quais são os outros possíveis impedimentos ao sucesso do seu projeto, que podem necessitar de novas narrativas de histórias.

Todas as atividades devem ser realizadas sob constante monitoramento do ambiente, que é realizado ouvindo conversas e observando o comportamento das pessoas. Como o contexto evolui sem cessar, o monitoramento deve acontecer a todo o momento, pois uma mudança importante pode invalidar uma programação.

\section{Exemplo de aplicação do processo}

Para exemplificar o método exposto, será apresentado exemplo de uma história narrada no contexto do gerenciamento de projetos de TI. 


\section{Propósito da história}

Convencer usuários da necessidade de construção de um novo sistema para substituir o atual, que utiliza tecnologia ultrapassada.

\section{Situação existente}

Os usuários ouviram palestra proferida por um adversário do projeto, sugerindo que o sistema atual seria muito bom, e a tecnologia utilizada - linguagem Cobol com arquivos Isam - estaria resolvendo as necessidades satisfatoriamente. Questionou a necessidade de substituir algo que está funcionando corretamente.

\section{Situação desejada}

Os usuários deveriam estar convencidos de que o sistema atual deve ser substituído, pois é antigo, de difícil manutenção e possui problemas de arquitetura que o tornam de difícil evolução para satisfazer novos requisitos.

\section{História narrada}

Processo de construção da história: Assim que ouviu o analista falando sobre a satisfação do sistema em Cobol, o gerente visualizou um carro antigo e, pensando como analista de sistema, elaborou mentalmente uma lista de requisitos da pessoa que atualmente compra um carro, muitos dos quais não atendidos por um carro antigo, como baixo consumo e facilidade de manutenção. Foi obtida na Internet a fotografia de um veículo antigo, o Chevrolet Opala. Essa fotografia foi inserida em um slide no meio da apresentação do projeto.

\section{Agendamento}

- Data: 04/05/2005.

- Local: auditório da organização.

- Ouvintes: todos os colaboradores da organização.

- Narrador: gerente do projeto do novo sistema, que deve substituir o atual.

Narrativa: O gerente do projeto exibiu o slide com a foto do veículo antigo, um "Opalão", como foi por ele denominado, e então despertou a atenção dos ouvintes perguntando: - Quem não se lembra do Opala? Continuou explicando que o Opala era o sonho de consumo de toda uma geração, um carro que conferia status e conforto ao seu usuário e atendia a todos os requisitos da época, mas o tempo passou, a tecnologia evoluiu e o combustível ficou mais caro. O "Opalão" deixa saudades de uma época das nossas vidas, mas a dificuldade em adquirir peças e encontrar um mecânico que conheça o carro, bem como o alto consumo de combustível fazem com que manter o veículo seja antieconômico. É o que acontece com o nosso sistema em Cobol: uma linguagem que resolve o problema, mas está cada vez mais difícil encontrar programadores e a arquitetura exige muito trabalho de manutenção, o que estressa os técnicos envolvidos.

\section{$\mathrm{O}$ que aconteceu}

Vários elementos da platéia demonstraram ter sofrido impacto emocional, ao se invocar o Opalão e sua época. Provavelmente esse impacto aconteceu apenas com a média e alta gerência, pessoas com idade entre 40 e 50 anos, que viveram os tempos de glória do veículo. Em conseqüência, a pessoa que estava afirmando que o sistema atual era suficiente aquietou-se e os tomadores de decisão passaram a apoiar o projeto de um novo sistema com mais confiança. O boato de que o sistema atual era "bom" foi anulado, e algum tempo depois o projeto teve início. Foram proferidas outras duas palestras nas quais essa história foi recontada.

\section{CONCLUSÃO}

O presente artigo mostrou que a narrativa de histórias consiste em uma técnica de gestão do conhecimento aplicável no gerenciamento de projetos de TI, contribuindo com o gerenciamento de projetos à medida que facilita a comunicação entre as pessoas. A história permite a construção de um significado compartilhado entre os envolvidos no projeto, alinhando pensamentos e ações numa área cujo produto e matéria-prima não podem ser vistos, tampouco tocados.

Até o presente momento, nenhum dos projetos em que a técnica foi utilizada chegou ao fim. No entanto, os gerentes consultados foram favoráveis quanto ao cumprimento dos propósitos de cada narrativa utilizada. Os dados levantados consideraram as narrativas de histórias aplicáveis em todas as áreas de conhecimento do PMBOK®. Dessa forma, pode-se concluir que a narrativa de histórias é instrumento útil no gerenciamento de projetos de TI.

\section{As principais constatações são as seguintes:}

c a principal fonte de histórias utilizada pelos gerentes é a experiência, de modo que gerentes com mais vivência possuem mais histórias próprias para contar;

- o propósito mais comum de uso das narrativas é para motivação da equipe, bem como têm facilitado a socialização de conhecimentos importantes na gestão de projetos de TI; c os gerentes empregam narrativas de histórias de forma intuitiva para atingir os propósitos identificados na literatura.

Durante a realização da pesquisa, surgiram várias oportunidades para a aplicação da técnica de narrativas de histórias no ambiente estudado, o que evidencia a sua utilidade prática no gerenciamento de projetos de TI. Por exemplo, houve 
interesse por sua aplicação nos projetos já em andamento nas organizações pesquisadas, o que permitiu aplicação do método desenvolvido.

O reaproveitamento de algumas das histórias dá indício de que um catálogo seria de grande utilidade para o gerente. A Internet também foi utilizada na busca de histórias, mas mostrou-se de pouco valor, pois falta um mecanismo que permita efetuar buscas de acordo com o propósito. Por isso, como solução para este problema, sugere-se estudar um mecanismo de armazenagem e indexação automatizada de histórias para localizar narrativas de acordo com o propósito. Essa técnica permitirá que o gerente possa encontrar mais facilmente o que busca. Devido a essa carência, as fontes

\section{REFERÊNCIAS}

ABMA, T. A. Learning by telling: storytelling workshops as an organizational learning intervention. London: Sage Publications, 2003.

AMTOFT, M. Storytelling as a support tool for project management. Hørsholm: [s. n.], 2002.

CAMILLE, H. J.; WILLIAN, C. M. Organizational storytelling: it makes sense. Business Horizons , v. 47, n. 4, p. 23-32, July/Aug. 2004.

CARROL, C. E. The strategic use of the past and future in organizational change: introduction. Joumal of organizational change management, v. 15, n. 6, p. 556-562, 2002.

CEGALLA, D. P. Dicionário de dificuldades da língua portuguesa. Rio de Janeiro: Nova Fronteira, 1999.

DENNEHY, R. F. How storytelling ignites action in knowledgeera organizations. Journal of Organizational Change Management, Yorkshire, 2001.

DENNING, Stephen. Where you shouldn't use a story. In: STORYTELLYING: passport to 21st century. Disponível em: $<$ http://www.creatingthe21stcentury.org/Intro9-where-not-to. html >. Acesso em: 30 maio 2005a.

$\overline{82, \text { May 2004a. }}$

. Telling tales. Harvard Business Review, Watertown ,v.

The leaders guide to storytelling: mastering the art and disciplines of business narrative. San Francisco, CA: Jossey-bass, 2005 .

Two modes of knowing: abstract and narrative. Storytelling: passport to 21st century. Disponível em: < http://www. creatingthe21stcentury.org/Intro3a-Scientific-triumphalism.html > . Acesso em: 30 maio 2004.

ECHEVERRÍA, Rafael. Ontologia del lenguage. Santiago: Dólmen Ediciones, 1997. mais bem-sucedidas foram conversas com gerentes, que se mostraram sempre dispostos a compartilhar suas histórias.

A história narrada em uma sessão coletiva demonstrou surtir resultados. Algumas histórias poderiam ser aplicadas em um contexto diferente, constituído de apenas duas pessoas, no qual há um diálogo, uma troca de informações. No entanto, isto não ocorreu na presente pesquisa, mas fica como sugestão para futuros trabalhos. Uma nova pesquisa poderia investigar as diferenças entre a narrativa para o coletivo e a voltada para o indivíduo.

\section{Artigo submetido em 13/12/2007}

e aceito em 22/08/2008.
. Reflexão, diálogo e ética nas organizações. 2004. Disponível em: < http://www.uniethos.org.br/Uniethos/Documents/ reflexao13WEB.pdf>. Acesso em: 22 mar. 2005.

GARGIULO, Terrence L. The strategic use of stories in organizational communication and learning. New York: M. E. Shape, 2005.

HALL, R.; ANDRIANI, P. Managing knowledge associated with innovation. Journal of Business Research, New York , v. 56, n. 2, p. 145-152, Feb. 2003.

KAHAN, Seth Weaver. Bringing us back to life: storytelling and the modern organization. Information Outlook, p. 26, May 2001.

KAMARA, J. M.; ANUMBA, C. J.; CARRILLO, P. M. A clever approach to selecting a knowledge management strategy. International Joumal of Project Management, Apr. 2002.

KOUZES, J. Posner, B. O desafio da liderança. [S. 1.]: Campus, 1997

LIPMAN, Doug. Improving your storytelling. Arkansas: August House Publishers, 1999.

LUFTMAN, Jerry et al. Managing the information technology resource: leadership in the information age. [S. 1.]: Prentice Hall, 2002. Cap. 10.

MATURANA, Humberto. A ontologia da realidade. Belo Horizonte: UFMG, 1997.

MCCLOKEY, Deirdre; KLAMEY, Arjo; SOLOW, Robert M. The consequences of economic rhetoric. [S. 1.]: Cambridge University Press, 1998.

MEYERS, P.; WILEMON, D. Learning in new technology development teams. Journal of Product Innovation Management, v. 6, n.2, p. 79-88, June 1989.

MORESI, E. A. D. (Org.). Manual de metodologia da pesquisa. Brasília: Universidade

Católica de Brasília, 2004. 
NONAKA, I; TAKEUCHI, H. Criação de conhecimento na empresa. [S. 1.]: Campus, 1997.

PMBOK. A guide to the project management body of knowledge. 1st ed. Pennsylvania: Project Management Institute, 2000.

. A guide to the project management body of knowledge. 3rd ed. Pennsylvania: Project Management Institute, 2004.

PRUSAK, Larry. What do really CEOs do?. In: STORYTELLING: passport to 21st century. Disponível em: <http://www. creatingthe21stcentury.org/Intro1c-Larry.html> . Acesso em: 28 maio 2004.

SCHINDLER, Martin. Harvesting project knowledge: a review of project learning methods and success factors. [S. l.]: Institute for Media and Communications Management, 2003.

SIMMONS, Annete. The story factor. Cambridge, MA: Basic Books, 2001.

SOMMERVILLE, Ian. Engenharia de software. 6. ed. São Paulo: Addison Wesley, 2003.

\section{APÊNDICE 1 \\ INSTRUMENTO DE COLETA DE DADOS}

1) Nome:

2) E-mail:

3) Nome da organização onde serve/trabalha:

4) Cargo ou função:

5) Qual é a sua formação acadêmica?

Graduação em

Especialização em

Mestrado em

Doutorado em

6) Qual é a sua faixa etária?

$\begin{array}{ll}\square \text { Menos de } 25 \text { anos } & \square \text { Entre 26 e } 30 \text { anos } \\ \square \text { Entre } 31 \text { e } 40 \text { anos } & \square \text { Entre 41 e } 50 \text { anos } \\ \square \text { Mais de } 50 \text { anos } & \end{array}$

7) Tempo de experiência em gerenciamento de projetos:

$\begin{array}{ll}\square \text { Menos de } 2 \text { anos } & \square \text { De } 2 \text { a } 5 \text { anos } \\ \square \text { De } 5 \text { a } 10 \text { anos } & \square \text { Mais de } 10 \text { anos }\end{array}$

STAVRI, Zoe; ASH, Joan. Does failure breed success: narrative analysis of stories about computerized provider order entry. Oregon: Oregon Health and Science University, 2003.

STEIN, Eric W. Organizational memory: review of concepts and recommendations for management. International Journal of Information Management, v. 15, n. 2, p. 17-32, 1995.

SWAP, Walter et al. Using mentoring and storytelling to transfer knowledge in the workplace. Journal of Management Information Systems, 2001.

TAYLOR, S.; FISCHER, D.; DUFRESNE, R. The aesthetics of management storytelling: a key to organizational learning. Management Learning, v. 33, n. 3, p. 313, Sep. 2002.

TERRA, J. C. GORDON, Cindy. Portais corporativos: a revolução na gestão do conhecimento. São Paulo: Negócio, 2002.

WILLIANS, T. Learning from projects. Journal of the Operations Research Society, v. 54, May, 2003.

WOO, J. et al. Dynamic knowledge map. [S. 1.]: A\&M University, 2003.

8) Com que freqüência você narra histórias no ambiente organizacional?

\begin{tabular}{|c|c|c|c|c|c|}
\hline Propósito da narrativa & Nunca & \begin{tabular}{|c|}
$\begin{array}{c}\text { Poucas } \\
\text { vezes }\end{array}$ \\
\end{tabular} & $\begin{array}{l}\text { Várias } \\
\text { vezes }\end{array}$ & \begin{tabular}{|c|} 
Muitas \\
vezes
\end{tabular} & Sempre \\
\hline Exemplificar a cultura da organização & $\square$ & $\square$ & $\square$ & $\square$ & $\square$ \\
\hline Modificar e controlar comportamentos & $\square$ & $\square$ & $\square$ & $\square$ & $\square$ \\
\hline Resolver problemas & $\square$ & $\square$ & $\square$ & $\square$ & $\square$ \\
\hline Gerenciar mudanças & $\square$ & $\square$ & $\square$ & $\square$ & $\square$ \\
\hline Estimular a criatividade/inovação & $\square$ & $\square$ & $\square$ & $\square$ & $\square$ \\
\hline $\begin{array}{l}\text { Melhorar a sua imagem, comunicar } \\
\text { quem você é }\end{array}$ & $\square$ & $\square$ & $\square$ & $\square$ & $\square$ \\
\hline Transferir conhecimento & $\square$ & $\square$ & $\square$ & $\square$ & $\square$ \\
\hline Treinar futuros líderes & $\square$ & $\square$ & $\square$ & $\square$ & $\square$ \\
\hline Transmitir sua visão de futuro & $\square$ & $\square$ & $\square$ & $\square$ & $\square$ \\
\hline Estimular a colaboração & $\square$ & $\square$ & $\square$ & $\square$ & $\square$ \\
\hline Silenciar rumores & $\square$ & $\square$ & $\square$ & $\square$ & $\square$ \\
\hline Motivar a equipe & $\square$ & $\square$ & $\square$ & $\square$ & $\square$ \\
\hline Outra: & $\square$ & $\square$ & $\square$ & $\square$ & $\square$ \\
\hline \multicolumn{6}{|c|}{$\begin{array}{l}\text { 9) Como você aprendeu a narrar histórias no exercício gerencial? } \\
\square \text { Em curso de gerenciamento } \\
\square \text { Não fui ensinado, narro histórias de forma intuitiva } \\
\square \text { Li em uma revista ou livro } \\
\square \text { Aprendi observando outros gerentes } \\
\square \text { Aprendi em conversa com amigos } \\
\square \text { Não conto histórias } \\
\square \text { Outra: }\end{array}$} \\
\hline
\end{tabular}


10) De que fonte você retira suas histórias?

\begin{tabular}{|c|c|c|c|c|c|}
\hline Fonte & Nunca & \begin{tabular}{|c|}
$\begin{array}{c}\text { Poucas } \\
\text { vezes }\end{array}$ \\
\end{tabular} & \begin{tabular}{|l|} 
Várias \\
vezes
\end{tabular} & \begin{tabular}{|c|} 
Muitas \\
vezes
\end{tabular} & Sempre \\
\hline Experiências que vivi & $\square$ & $\square$ & $\square$ & $\square$ & $\square$ \\
\hline Fábulas populares & $\square$ & $\square$ & $\square$ & $\square$ & $\square$ \\
\hline Música & 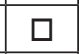 & $\square$ & $\square$ & $\square$ & $\square$ \\
\hline Livros, revistas ou jornais & $\square$ & $\square$ & $\square$ & $\square$ & $\square$ \\
\hline Televisão: novelas, filmes, telejornais & $\square$ & $\square$ & $\square$ & $\square$ & $\square$ \\
\hline $\begin{array}{l}\text { Conversas com amigos de outras } \\
\text { organizacõos }\end{array}$ & $\square$ & $\square$ & $\square$ & $\square$ & $\square$ \\
\hline Procuro histórias na minha organização & $\square$ & $\square$ & $\square$ & $\square$ & $\square$ \\
\hline Sites na Internet & $\square$ & $\square$ & $\square$ & $\square$ & $\square$ \\
\hline E-mail & $\square$ & $\square$ & $\square$ & $\square$ & $\square$ \\
\hline Lendas organizacionais & $\square$ & $\square$ & $\square$ & $\square$ & $\square$ \\
\hline Eu invento & $\square$ & $\square$ & $\square$ & $\square$ & $\square$ \\
\hline Outra: & $\square$ & $\square$ & $\square$ & $\square$ & $\square$ \\
\hline
\end{tabular}

11) Para que audiências você narrou ou narra histórias?

\begin{tabular}{|l|c|c|c|c|c|}
\hline \multicolumn{1}{|c|}{ Audiência } & Nunca & $\begin{array}{c}\text { Poucas } \\
\text { vezes }\end{array}$ & $\begin{array}{c}\text { Várias } \\
\text { vezes }\end{array}$ & $\begin{array}{c}\text { Muitas } \\
\text { vezes }\end{array}$ & Sempre \\
\hline Subordinados & $\square$ & $\square$ & $\square$ & $\square$ & $\square$ \\
\hline Clientes & $\square$ & $\square$ & $\square$ & $\square$ & $\square$ \\
\hline Fornecedores & $\square$ & $\square$ & $\square$ & $\square$ & $\square$ \\
\hline Companheiros & $\square$ & $\square$ & $\square$ & $\square$ & $\square$ \\
\hline Superiores & $\square$ & $\square$ & $\square$ & $\square$ & $\square$ \\
\hline Workshops na minha organização & $\square$ & $\square$ & $\square$ & $\square$ & $\square$ \\
\hline $\begin{array}{l}\text { Workshops fora da minha } \\
\text { organização }\end{array}$ & $\square$ & $\square$ & $\square$ & $\square$ & $\square$ \\
\hline $\begin{array}{l}\text { Conferências/palestras na minha } \\
\text { organização }\end{array}$ & $\square$ & $\square$ & $\square$ & $\square$ & $\square$ \\
\hline $\begin{array}{l}\text { Conferências/palestras fora da } \\
\text { minha organização }\end{array}$ & $\square$ & $\square$ & $\square$ & $\square$ & $\square$ \\
\hline Outra: & $\square$ & $\square$ & $\square$ & $\square$ & $\square$ \\
\hline
\end{tabular}

12) Em que áreas de conhecimento do $P M B O K \circledast$ você acha adequado utilizar narrativas de histórias?

\begin{tabular}{l|c|c|c|c|c|c}
\hline \multicolumn{1}{c|}{$\begin{array}{c}\text { Área de } \\
\text { conhecimento }\end{array}$} & $\begin{array}{c}\text { Não } \\
\text { sei }\end{array}$ & $\begin{array}{c}\text { Inade- } \\
\text { quado }\end{array}$ & $\begin{array}{c}\text { Pouco } \\
\text { adequado }\end{array}$ & Adequado & $\begin{array}{c}\text { Muito } \\
\text { adequado }\end{array}$ & $\begin{array}{c}\text { Totalmente } \\
\text { adequado }\end{array}$ \\
\hline $\begin{array}{l}\text { Gerenciamento de } \\
\text { integração }\end{array}$ & $\square$ & $\square$ & $\square$ & $\square$ & $\square$ & $\square$ \\
\hline $\begin{array}{l}\text { Gerenciamento de } \\
\text { escopo }\end{array}$ & $\square$ & $\square$ & $\square$ & $\square$ & $\square$ & $\square$ \\
\hline $\begin{array}{l}\text { Gerenciamento de } \\
\text { tempo }\end{array}$ & $\square$ & $\square$ & $\square$ & $\square$ & $\square$ & $\square$ \\
\hline $\begin{array}{l}\text { Gerenciamento de } \\
\text { custos }\end{array}$ & $\square$ & $\square$ & $\square$ & $\square$ & $\square$ & $\square$ \\
\hline $\begin{array}{l}\text { Gerenciamento de } \\
\text { qualidade }\end{array}$ & $\square$ & $\square$ & $\square$ & $\square$ & $\square$ & $\square$ \\
\hline $\begin{array}{l}\text { Gerenciamento de } \\
\text { recursos humanos }\end{array}$ & $\square$ & $\square$ & $\square$ & $\square$ & $\square$ & $\square$ \\
\hline $\begin{array}{l}\text { Gerenciamento de } \\
\text { comunicação }\end{array}$ & $\square$ & $\square$ & $\square$ & $\square$ & $\square$ & $\square$ \\
\hline $\begin{array}{l}\text { Gerenciamento de } \\
\text { riscos }\end{array}$ & $\square$ & $\square$ & $\square$ & $\square$ & $\square$ & $\square$ \\
\hline $\begin{array}{l}\text { Gerenciamento de } \\
\text { aquisições }\end{array}$ & $\square$ & $\square$ & $\square$ & $\square$ & $\square$ & $\square$ \\
\hline
\end{tabular}

13) Você gostaria de compartilhar conosco alguma história que já contou no ambiente organizacional? (opcional)

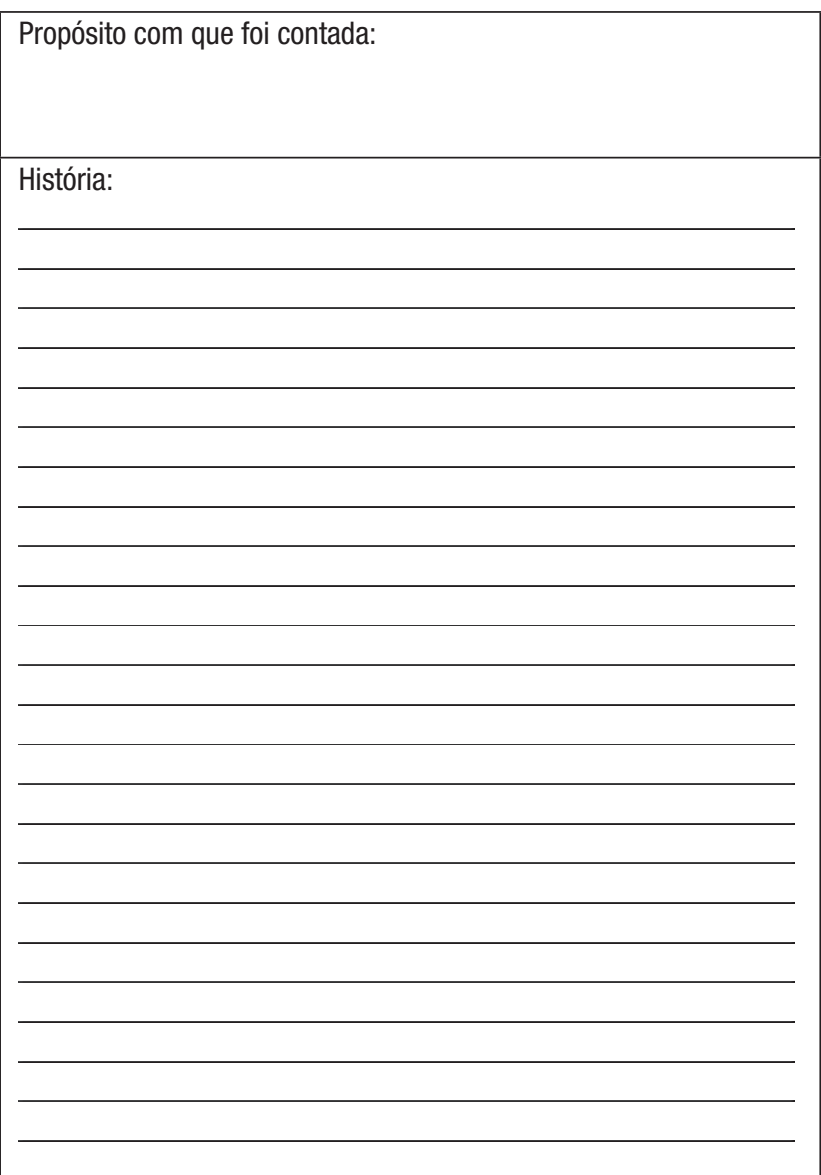

